\title{
Seasonal Dependence of ENSO Teleconnections over South America and Relationships with Precipitation in Uruguay
}

\author{
Gabriel CAZEs-Boezio \\ Instituto de Mecánica de Fluidos e Ingeniería Ambiental Prof. Ing. Oscar Maggiolo, Facultad de Ingeniería, \\ Universidad de la República, Montevideo, Uruguay \\ Andrew W. Robertson* And Carlos R. Mechoso \\ Department of Atmospheric Sciences, University of California, Los Angeles, Los Angeles, California
}

(Manuscript received 19 November 2001, in final form 7 July 2002)

\begin{abstract}
The El Niño-Southern Oscillation (ENSO) has an established impact on precipitation in Uruguay during austral spring (October-December). This impact is absent in peak summer (January-February), and returns weakly in fallwinter (March-July). Interannual and intraseasonal variability of the atmospheric circulation over South America and the South Pacific is investigated using the NCEP-NCAR reanalysis data for these seasons. The leading empirical orthogonal function (EOF) of seasonally averaged 200-hPa winds over South America is found to be associated with ENSO through a pronounced Walker cell component in all seasons. However, during spring, this pattern acquires an extratropical teleconnection that links the circulation over southeastern South America (SESA) with ENSO. This extratropical teleconnection disappears in summer, when the circulation over SESA is dominated by variability in the South Atlantic convergence zone. In fall, extratropical South America again becomes affected by a wavelike pattern that extends over the South Pacific, but it is uncorrelated with ENSO.

On intraseasonal timescales, a cluster analysis of daily geopotential height fields over the South Pacific sector reveals three wave train-like circulation regimes with similar structures in all seasons. During the transition seasons (but not summer), the frequencies of occurrence of two of these regimes are found to be significantly different from normal in years when the interannual wavelike EOFs are pronounced. Interannual anomaly patterns are constructed from the intraseasonal regimes according to these changes in their frequency of occurrence, and shown to resemble quite closely the interannual EOFs over the South Pacific sector. These results provide evidence that the interannual teleconnection patterns seen over the South Pacific in austral spring and fall-winter are due to changes in the frequency of occurrence and amplitude of intraseasonal circulation regimes. The Rossby wave source composited over ENSO years suggests that ENSO heating anomalies are able to trigger these changes in regime occurrence and amplitude during October-December through Rossby wave propagation, leading to the known ENSO teleconnection in austral spring. By contrast, the interannual teleconnection over the South Pacific during fall-winter appears to be due to essentially random changes in the frequency of occurrence of the intraseasonal circulation regimes, which are found to be much larger than during austral summer when no extratropical teleconnection pattern exists.
\end{abstract}

\section{Introduction}

Interannual variability of the atmospheric circulation over South America has mostly been studied in terms of its relationship with the El Niño-Southern Oscillation (ENSO). During the winter half-year April-October, Aceituno (1989) found that negative values of the

* Current affiliation: International Research Institute for Climate Prediction, Palisades, New York.

Corresponding author address: Dr. Gabriel Cazes-Boezio, Instituto de Mecánica de Fluidos e Ingeniería Ambiental Prof. Ing. Oscar Maggiolo, Facultad de Ingeniería, Universidad de la República, Julio Herrera y Reissig 565, Montevideo CP 11300, Uruguay.

E-mail: agcm@fing.edu.uy
Southern Oscillation index (SOI) were associated with an enhanced meridional gradient of geopotential height at midlatitudes over South America. No such relationship was found during the summer half-year NovemberApril. Pisciottano et al. (1994), however, found a more complex seasonal dependence in rain gauge data from stations in Uruguay. According to Pisciottano et al. (1994), in Uruguay there is a break in the ENSO relationship with rainfall anomalies only during high summer: during El Niño events, rainfall is more likely to be above the climatological median from November of an El Niño year to January of the following year, and again during March-July. The relationship during La Niña is almost the reverse, with reduced rainfall more likely from October to December of a La Niña year, and from March to July of the following year. The high- 
summer break in the ENSO-rainfall relationship during January-February was found to be especially pronounced during La Niña.

Grimm et al. (2000) found almost equivalent barotropic dipolelike circulation anomalies over the subtropical Pacific and Atlantic Oceans during ENSO events, with seasonal modulation of amplitude and position. These dipolelike circulation anomalies consist, during El Niño (La Niña), of episodes of cyclonic (anticyclonic) anomalies to the west of southeastern South America (SESA) and anticyclonic anomalies to the east. They related these dipoles to precipitation anomalies over SESA through the vorticity advection at upper levels, and the meridional advection of moisture at low levels.

Over tropical and subtropical South America, the circulation is dominated by a monsoon system during the summertime, with a pronounced South Atlantic convergence zone (SACZ). On interannual timescales, Robertson and Mechoso (2000) found that an anomalous cyclonic (anticyclonic) large-scale eddy accompanies an intensified (diffuse) SACZ, with a region of anomalous descent (ascent) to the southwest of the SACZ. This feature was found to be independent of ENSO during the January-March season studied. Southeastern South America tends to be dryer when the SACZ is pronounced, due both to compensating anomalous descent as well as a reduction in the southward advection of moisture east of the Andes. Barros et al. (2000) also found that reduced (increased) precipitation in southern Brazil, most of Uruguay, and northeastern Argentina is associated with a strong (weak) SACZ as well as a northward (southward) displacement of it, while increased (reduced) precipitation occurs farther south in Argentina.

Since the atmosphere's intrinsic modes of tropical and extratropical variability have timescales of less than a season, it is logical to consider interannual variability in terms of the statistics of intraseasonal variations. The intensity of the SACZ varies considerably on submonthly (Liebmann et al. 1999) and intraseasonal (Nogués-Paegle and Mo 1997) timescales. In both cases, a meridional seesaw in upper-level cloud and precipitation characterizes the variability. Drought in southern Brazil is associated with an intensified SACZ on intraseasonal timescales (Casarin and Kousky 1986). Over the Pacific-South America sector, Mo and Ghil (1987), Kidson (1988, 1991), and Ghil and Mo (1991) have found intraseasonal patterns dominated by zonal wavenumber 3 , now known generically as the Pacific-South America (PSA) pattern. Mo and Higgins (1998) have found associations between these modes and the outgoing longwave radiation (OLR) in the tropical Pacific and Indian Oceans. Nogués-Paegle et al. (2000) have found evidence that a strong dipolar convection pattern spanning the SACZ and the subtropical plains tends to be related to both the Madden-Julian oscillation (MJO), as well as a PSA-like pattern on a timescale of 20-30 days.
The response of the extratropical atmosphere to equatorial El Niño SST anomalies can be understood in terms of (i) Rossby waves emanating from anomalous sources in the Tropics and subtropics (Hoskins and Karoly 1981; Sardeshmukh and Hoskins 1988), and (ii) the interaction of these anomalous stationary waves with extratropical dynamics. The latter interactions include those with the climatological stationary waves (Branstator 1985) and transient eddies (Held et al. 1989). In order to understand the interactions between tropical forcing and midlatitude dynamics in more detail, it is necessary to identify the extratropical atmosphere's intrinsic modes of variability and then to investigate the influence of tropical forcing on these modes. It is well established that intraseasonal variability in the extratropics of the Northern Hemisphere is characterized by certain large-scale patterns that appear repeatedly at fixed geographical locations. These patterns were termed Grosswetterlagen by Bauer (1951), and have since been systematized in terms of teleconnection patterns (Wallace and Gutzler 1981) or persistent anomalies (Dole and Gordon 1983) in midtropospheric height fields. Mo and Ghil (1987) have found persistent anomalies with recurrent spatial patterns in the Southern Hemisphere extratropics as well.

Legras and Ghil (1985) studied low-frequency planetary flow regimes in a nonlinear, equivalent barotropic model with topography. Multiple unstable stationary solutions were obtained as a result of the nonlinearities of the model; the time-dependent solutions showed persistent sequences of anomalies that occurred in the vicinity of the model's unstable stationary solutions. The composite flow pattern of these persistent sequences were found to be similar to the corresponding nearby equilibria, permitting the persistent sequences to be defined as quasi-stationary flow regimes. Regimes have been defined in observed data as well, from clustering (Cheng and Wallace 1993; Mo and Ghil 1987), maxima in the probability density function of the large-scale, low-frequency flow (Kimoto and Ghil 1993), or by quasi stationarity (Ghil and Childress 1987; Vautard 1990). If, during a particular year and season, intraseasonal regimes with a certain structure and polarity occur more often than usual, they will leave a residue after seasonal averaging. If, in addition, tropical forcing anomalies associated with El Niño tend to favor one regime over another, the extratropical response will be characterized in terms of the regime patterns. Several studies have argued that the response to El Niño over the North Pacific-North American sector can be interpreted in this way (Horel and Mechoso 1988; Molteni et al. 1993; Robertson and Ghil 1999; Farrara et al. 2000).

The aim of this paper is to investigate the mechanisms that determine the seasonality of interannual circulation anomalies and teleconnections over South America and to examine to what extent these interannual anomalies can be interpreted in terms of intraseasonal flow regimes over the South Pacific. Our analysis is based on the 
seasonal definitions that best characterize the influence of ENSO on precipitation in Uruguay according to Pisciottano et al. (1994); these "seasons" are OctoberDecember, January-February, and March-July. EOFs of seasonal mean 200-hPa wind vector fields are computed over South America, and the associated principal component (PC) time series are then regressed onto global fields to investigate remote teleconnections, comparing with analogous regression maps constructed from an index of precipitation over Uruguay. The most frequently occurring intraseasonal patterns over the South Pacific sector are constructed using a $K$-means clustering analysis, following Michelangeli et al. (1995). Conditional sampling is then used to determine relationships with the interannual South American EOFs.

The datasets used are described in section 2. Section 3 contains the study of interannual variability through EOF analysis, and section 4 describes the study on the intraseasonal timescale. We conclude with a summary of findings and conclusions in section 5.

\section{Data}

Our study of interannual timescales is based on seasonal means constructed from the 1948-97 National Centers for Environmental Prediction-National Center for Atmospheric Research (NCEP-NCAR) reanalysis dataset (Kalnay et al. 1996), given on a $2.5^{\circ}$ grid. To investigate relationships with sea surface temperature (SST) we use the Global Sea Ice and Sea Surface Temperature (GISST) 1903-94 dataset (Rayner et al. 1995). To check the consistency of selected results with a database independent from the reanalysis we take the time series of precipitation in Uruguay. This time series is a simple arithmetic average of data from 13 rainfall gauges distributed throughout the country, provided by the Direccion Nacional de Meteorologia of Uruguay, for the period 1914-99. For the study of circulation regimes in the intraseasonal band over the extratropical South $\mathrm{Pa}-$ cific we use the daily mean geopotential height at 700 $\mathrm{hPa}$ from the NCEP-NCAR reanalysis. The extended interval from 1948 to 1998 is used to maximize the sample size.

\section{Empirical orthogonal function analysis}

We construct EOFs of seasonal mean 200-hPa winds in a domain covering South America $\left(60^{\circ} \mathrm{S}-10^{\circ} \mathrm{N}, 30^{\circ}-\right.$ $90^{\circ} \mathrm{W}$ ), for the austral spring (October-December), summer (January-February), and fall (March-July). The $200-\mathrm{hPa}$ circulation is chosen because it characterizes both extratropical dynamical processes as well as the upper part of the tropical Walker cells. The seasonally averaged zonal and meridional wind are combined into a single vector, and the EOFs are then computed as the eigenvectors of the associated covariance matrix. The leading EOFs were found to be insensitive to using the correlation matrices, selecting a smaller domain cen- tered on SESA $\left(50^{\circ}-10^{\circ} \mathrm{S}, 20^{\circ}-70^{\circ} \mathrm{W}\right)$, and to the application of a varimax-type rotation of the EOFs (Richman 1986). The present results are not rotated.

The EOF analysis was first performed over the 195897 interval. However the second PC for the March-July season was found to exhibit a jump around 1968. This PC was found to be highly correlated with precipitation over Uruguay in the same season, but the precipitation time series shows no such jump. We repeated the EOF analysis for the same three seasons but using data over the periods 1948-97 and 1968-97, and found the EOFs to be very similar in both cases. We present below the results of the 1968-97 analysis, which allows us to compute correlations with precipitation in Uruguay without difficulties.

\section{a. The October-December season}

Figure 1 shows the leading October-December EOF (EOF-1), whose PC time series accounts for $21 \%$ of the variance. The EOF is plotted in terms of global regression maps of the normalized PC with 200-hPa winds (Fig. 1a), 850-hPa winds (Fig. 1b), SST (Fig. 1c), and 500-hPa omega vertical velocity (Fig. 1d). In Figs. a,b, vectors are restricted to grid points where at least one wind component has a statistically significant correlation with the PC at the $95 \%$ level, based on a two sided $t$ test of the correlation coefficient, with the number of effective degrees of freedom estimated separately at each grid point following Chen (1982). Significant regions are shaded in Figs. 1c,d.

Over South America, EOF-1 consists of an anticyclonic vortex centered over SESA (with a wavelength equivalent to a zonal wavenumber of about 6), together with westerly anomalies over northern South America (Fig. 1a). Outside of the domain of EOF analysis, there are twin anticyclonic circulations over the tropical $\mathrm{Pa}$ cific on either side of the equator, together with a deep vortex over the South Pacific. The strong relationship between EOF-1 and El Niño is indicated by the regression maps of low-level winds, SST and omega in Figs. 1b-d. Positive SST anomalies over the central and eastern equatorial Pacific are associated with upper-level easterly and low-level westerly wind anomalies over the equatorial Pacific, which are characteristic of a weakened Walker cell and of the linear response to an equatorial heating anomaly over the eastern equatorial $\mathrm{Pa}-$ cific (Gill 1980). The correlation coefficient of PC-1 with the Niño-3.4 $\left(5^{\circ} \mathrm{S}-5^{\circ} \mathrm{N}\right.$ and $\left.170^{\circ} \mathrm{W}-120^{\circ} \mathrm{E}\right)$ index is 0.60. Over South America, EOF-1 is associated with anomalous descent over the SACZ and anomalous ascent over SESA (Fig. 1d). Consistent with these vertical motion anomalies, PC-1 is found to be significantly correlated (at a 95\% level) with precipitation over Uruguay, with a correlation coefficient of 0.49 . This is consistent with the known correlation between ENSO and Uruguay precipitation during October-December (Pisciottano et al. 1994). 
(a) u,v 200-hPa

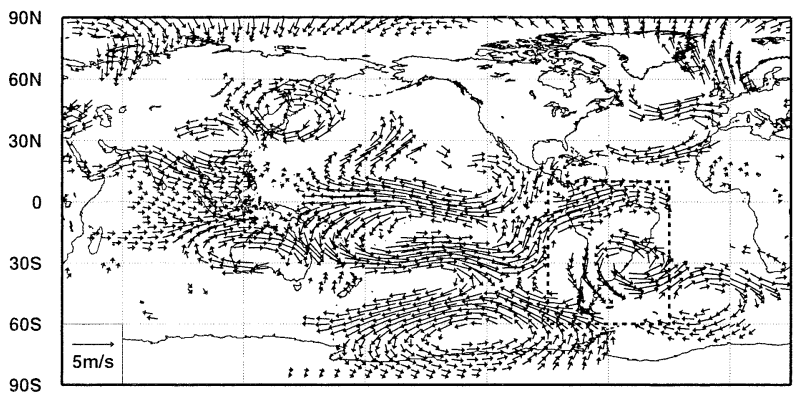

(c) SST

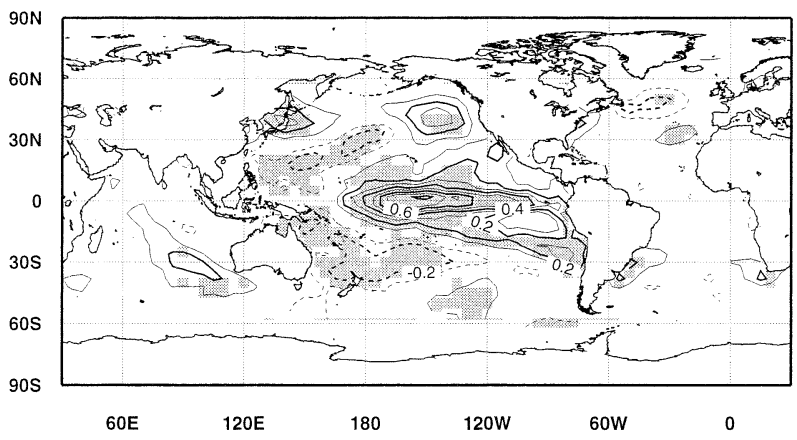

(b) u,v $850-\mathrm{hPa}$

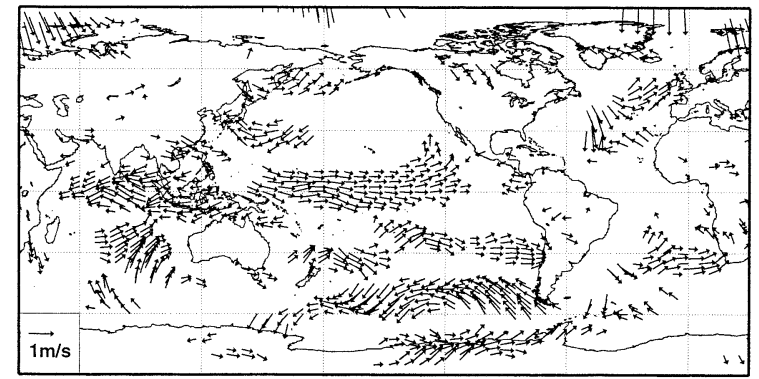

(d) omega 500-hPa

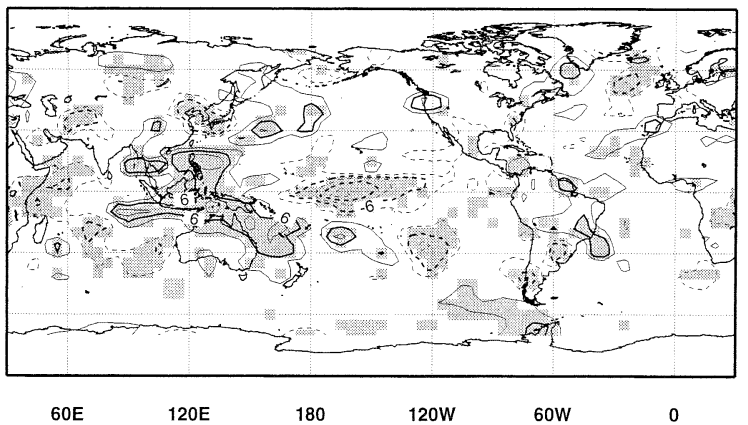

FIG. 1. Regression maps of Oct-Dec PC-1 with (a) 200-hPa winds, (b) 850-hPa winds, (c) SST, and (d) 500-hPa omega vertical velocity. Magnitudes correspond to one std dev of the respective PC time series. The domain of the EOF analysis covers South America, as indicated by the dashed box in (a). Only vectors whose correlations with the respective PC are statistically significant to the $95 \%$ level are plotted (see text for details on the statistical significance computation). Contour interval is $0.1^{\circ} \mathrm{C}$ in (c) and $1 \times 10^{-3} \mathrm{~Pa} \mathrm{~s}^{-1}$ in (d).

The EOF-2 (not shown), whose PC accounts for $18 \%$ of the variance, is not well correlated with precipitation in Uruguay, nor with ENSO.

\section{b. The January-February season}

EOFs-1 and -2 for the peak austral summer season (whose respective PCs account for $23 \%$ and $18 \%$ of the variance) are shown in Figs. 2 and 3, respectively. As in October-December, the leading EOF of 200-hPa winds over South America during January-February is associated with ENSO, with typical patterns of wind, omega, and SST over the tropical Pacific (Fig. 2). The correlation coefficient with the Niño-3.4 index is 0.67. However, in the austral summer there is no extratropical wavelike circulation pattern over the South Pacific, and the correlation with precipitation in Uruguay is not significantly different from zero. Over SESA, there is nonetheless a dipole in omega that is situated slightly farther north and thus does not impact precipitation over Uruguay. This feature illustrates the complexity of ENSO teleconnections even within SESA, as highlighted by Grimm et al. (2000). Compared to Fig. 1, the ENSOrelated South American circulation anomalies have a much stronger Walker circulation component, and this extends into the Atlantic and Indian Oceans, with significant SST anomalies over the latter.

EOF-2 is very similar to the leading EOF in the southeastern South American domain found by Robertson and Mechoso (2000) for the January-March season. In the polarity plotted, EOF-2 is associated with a strong anticyclonic vortex at $200 \mathrm{hPa}$ centered over SESA, similar to that seen in October-December in Fig. 1. However, as found by Robertson and Mechoso (2000), this SACZ-SESA vortex is not teleconnected with El Niño in January-February, but is correlated instead with dipolar SST anomalies over the southwest Atlantic (Fig. $3 \mathrm{c})$. There are also anomalous northerlies at the 850$\mathrm{hPa}$ level in the low-level jet (LLJ) region to the east of the Andes (Fig. 3b). Consistently, PC-2 is found to be highly correlated with precipitation in Uruguay $(r=$ $0.62)$, while the correlation of PC-2 with the Niño-3.4 index is not significant.

\section{c. The March-July season}

Again during March-July it is EOF-1 (whose PC accounts for $28 \%$ of variance) that is associated with El Niño-like patterns in winds, SSTs, and vertical motion, although anomalies over the Atlantic are much more 
(a) u,v 200-hPa

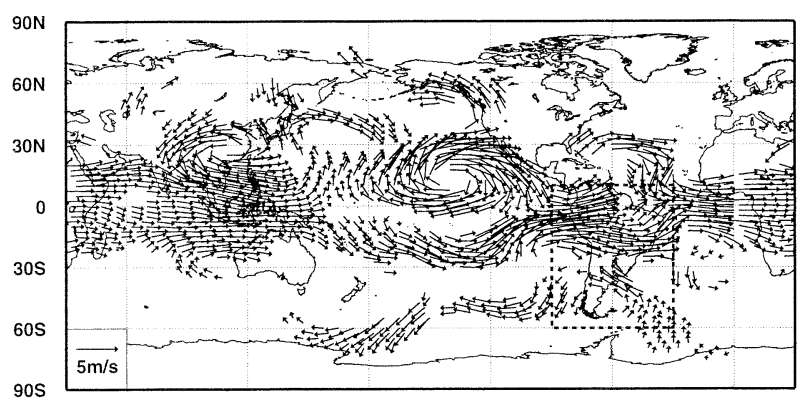

(c) SST

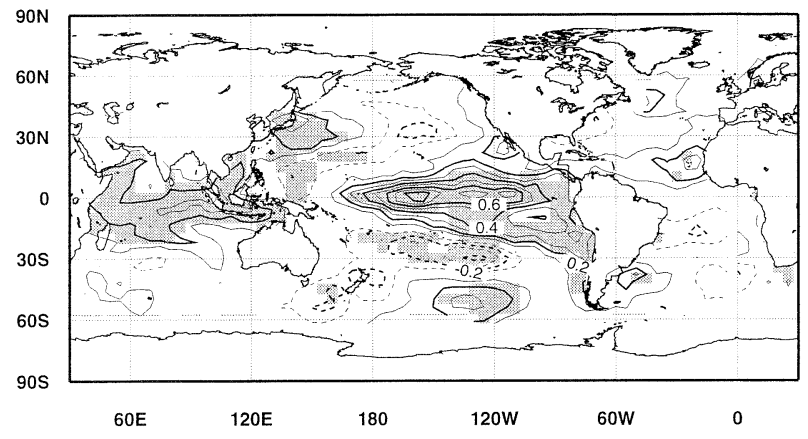

(b) u,v 850-hPa

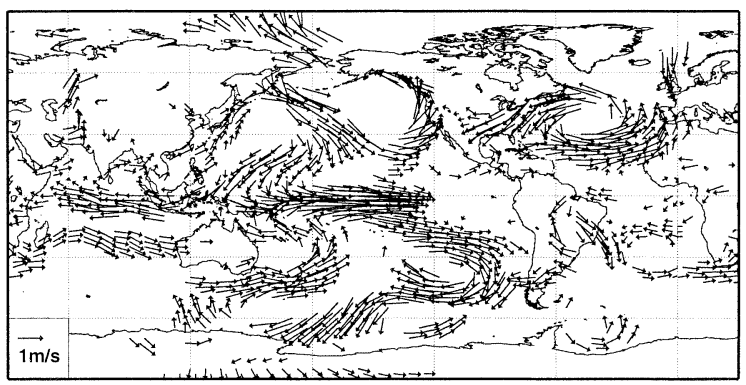

(d) omega $500-\mathrm{hPa}$

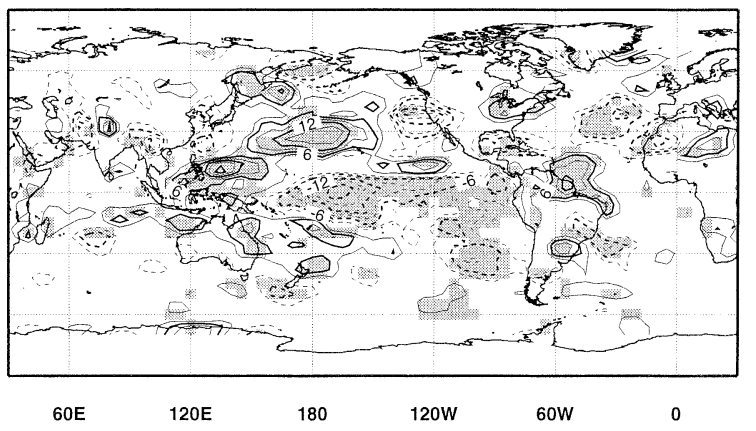

FIG. 2. Same as in Fig. 1 but for Jan-Feb PC-1.

(a) u,v 200-hPa

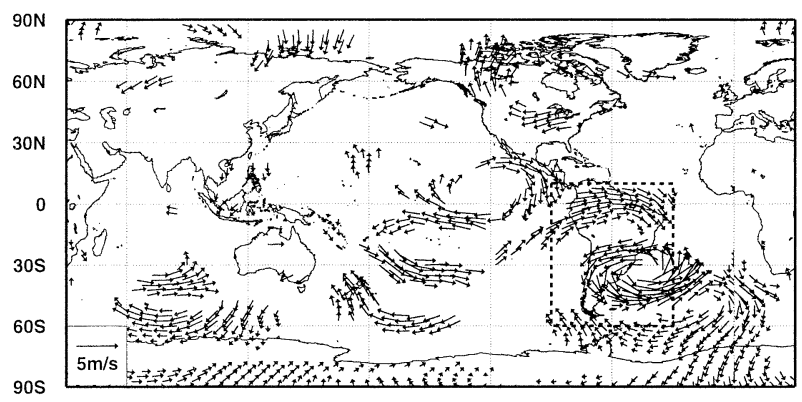

(c) SST

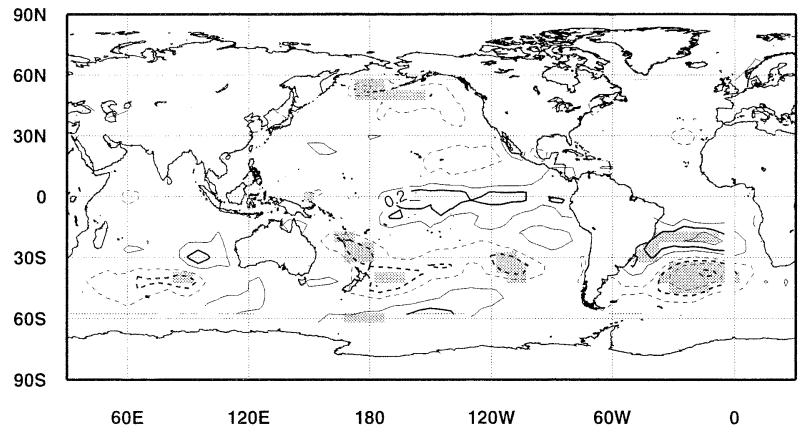

(b) u,v 850-hPa

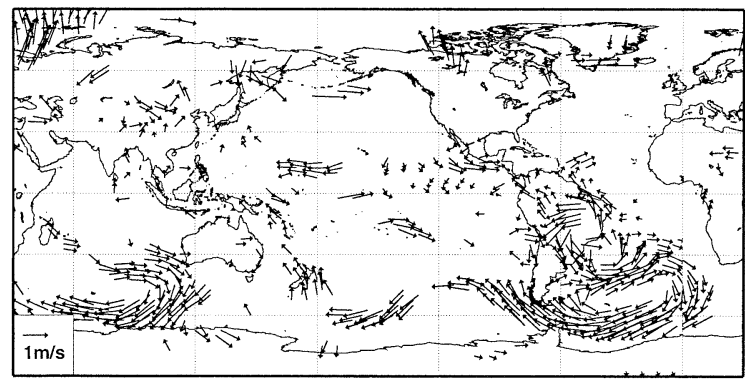

(d) omega 500-hPa

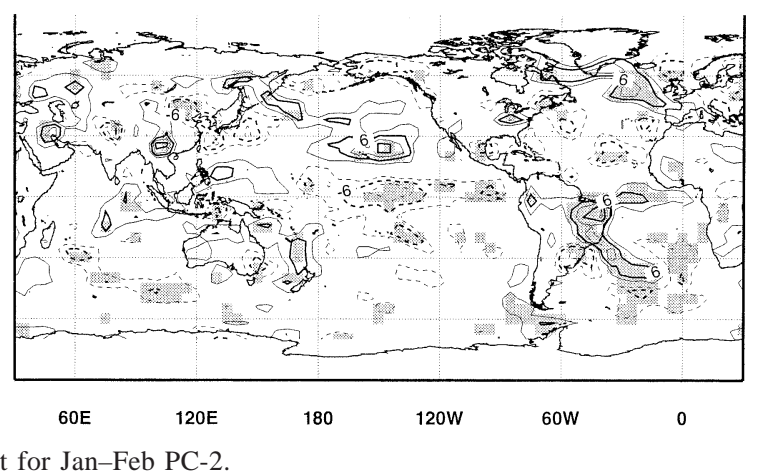


(a) u,v 200-hPa

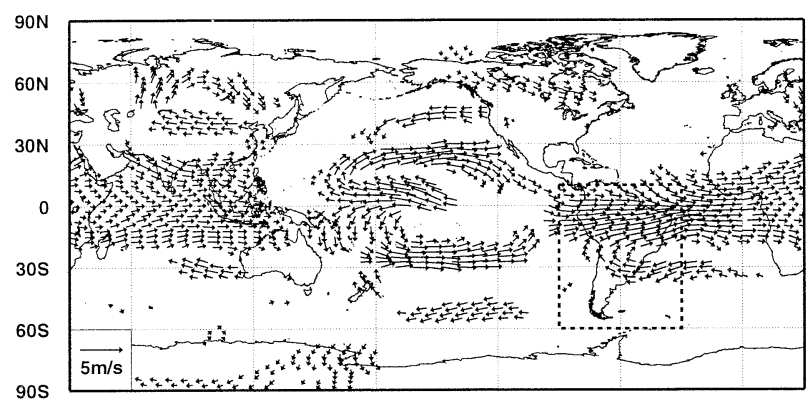

(c) SST

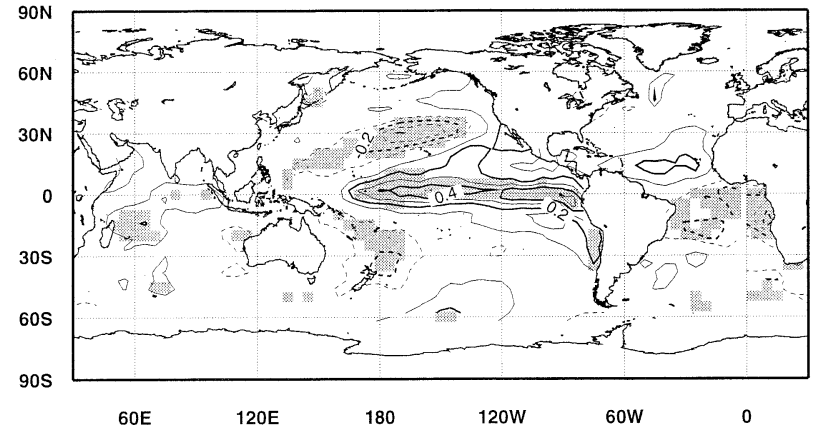

(b) u,v 850-hPa

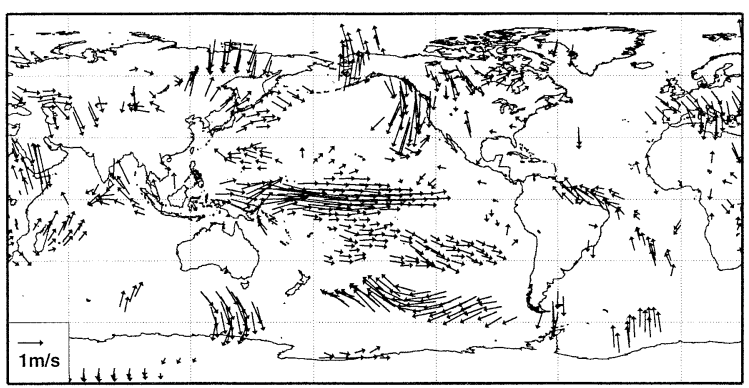

(d) omega $500-\mathrm{hPa}$

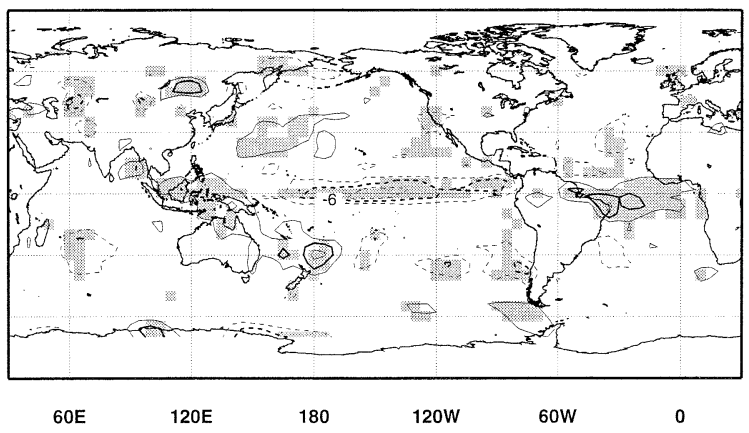

FIG. 4. Same as in Fig. 1 but for Mar-Jul PC-1.

pronounced than during austral spring and summer seasons (Fig. 4). As in summer, there is little sign of an extratropical teleconnection between the tropical Pacific and SESA. The correlation coefficient between PC-1 and the Niño-3.4 index is 0.67 , with no significant correlation with Uruguay precipitation.

The second EOF (Fig. 5) shows a striking wavelike pattern, arching far poleward from the western equatorial Pacific before turning equatorward into South America. PC-2 (19\% of variance) has a positive correlation with precipitation in Uruguay $(r=0.70)$, but is not significantly correlated with SST or vertical motion over the tropical Pacific. As in summer, there are significant SST correlations over the southwest Atlantic.

\section{d. Summary and sensitivity experiments}

The leading EOF of seasonally averaged 200-hPa winds over South America is associated with ENSO throughout the spring, summer, and fall seasons. However, it is only during spring that this pattern includes an extratropical teleconnection that links the circulation over SESA with ENSO. In summer, the extratropical teleconnection disappears, and the circulation over SESA is mostly related to variability of the SACZ (EOF2). In fall, extratropical South America again experiences interannual circulation variability with a wavelike pattern that extends upstream over the South Pacific, and significant correlations with Uruguay rainfall. However, this wave train is not significantly correlated with ENSO. These features can be recovered independently by simply regressing seasonal mean precipitation over Uruguay with the 200-hPa wind field, as shown in Fig. 6. This confirms that these patterns are not artifacts of the EOF method, and demonstrates that interannual anomalies in precipitation over Uruguay are 1) associated with the leading modes of circulation variability over SESA, and 2) that these modes exhibit pronounced planetary-scale teleconnections. These characteristics point toward a good deal of potential seasonal-to-interannual predictability in Uruguay precipitation.

In order to justify a posteriori our seasonal "poolings" of months in the EOF analyses Figs. 1-3, as well as to further assess the seasonality of the teleconnections, we have computed EOFs for individual calendar months. Despite the increased sampling variability, these single calendar month EOFs generally reflect their seasonal mean counterparts in Figs. 1-3. We show EOF1 for October, January, and April in Fig. 7. For October and November, EOF-1 is very similar to EOF-1 of October-December, while January's EOF-1 and February's EOF-2 show a vortex over SESA similar to that found in January-February's EOF-2. In April, May, and July, EOF-1 is similar to March-July's EOF-2, which resembles the June EOF-3. The EOFs for December and March show less clear correspondence, perhaps because 
(a) u,v 200-hPa

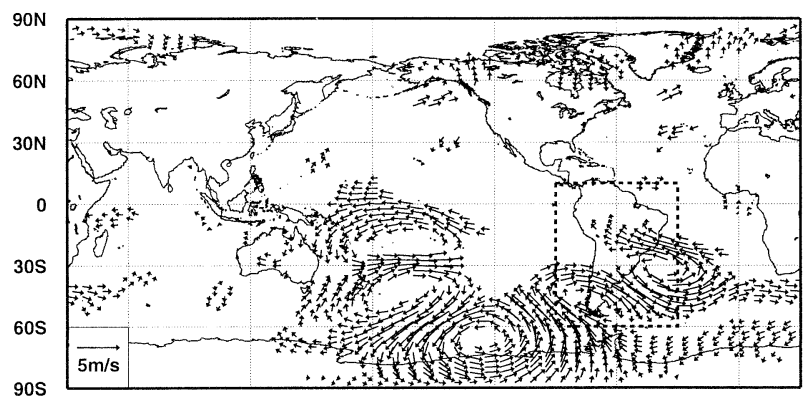

(c) SST

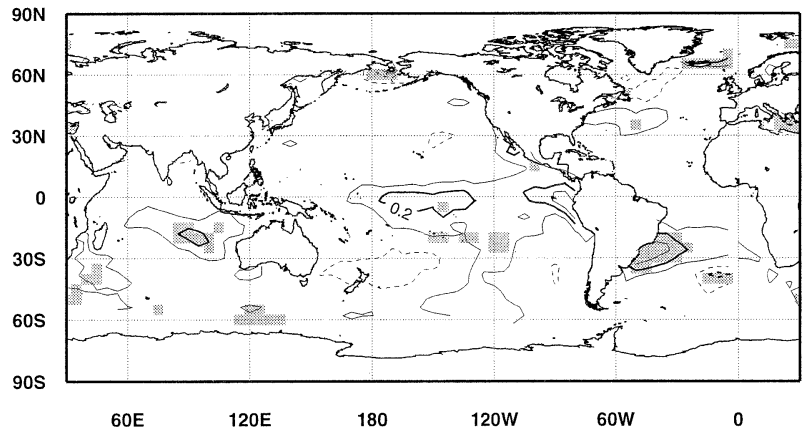

(b) $u, v 850-\mathrm{hPa}$

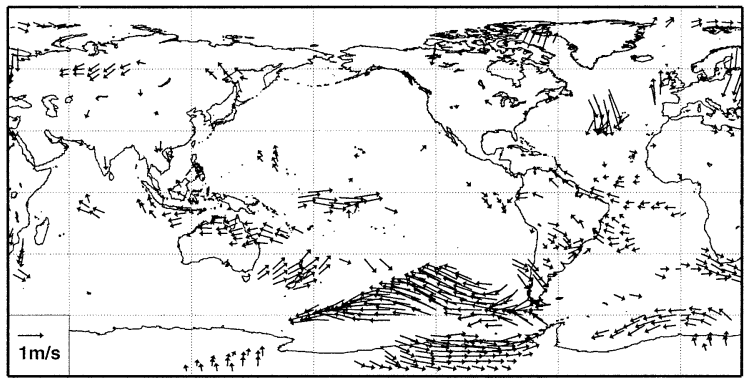

(d) omega $500-\mathrm{hPa}$

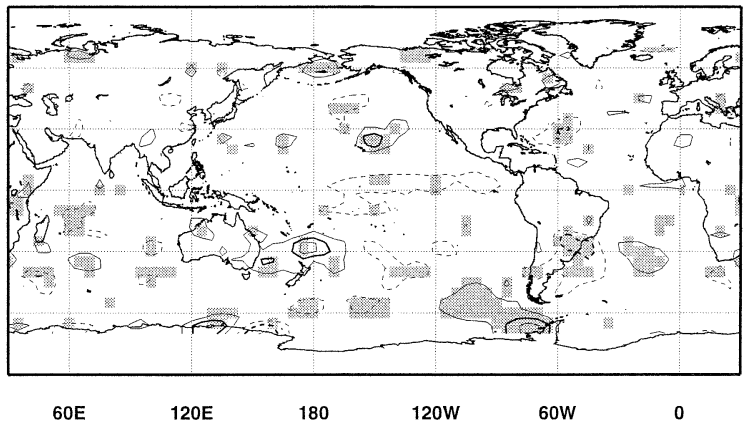

they are "transitional months" between the different coherent seasonal behaviors identified.

\section{Regimes of intraseasonal variability \\ a. Data preprocessing and methodology}

In this section we test the hypothesis that the interannual teleconnections over the extratropical South Pacific, found in the EOF analysis, can be understood as interannual modulations in the frequency of occurrence of intraseasonal midlatitude circulation regimes over the South Pacific. A $K$-means cluster analysis is used to determine the most frequently occurring (low pass filtered) daily $700-\mathrm{hPa}$ geopotential height maps, using the method described by Michelangeli et al. (1995). For each of the seasons defined by Pisciottano et al. (1994), daily data are (i) low pass filtered at 10 days, (ii) deseasonalized by subtracting the mean seasonal cycle, averaged over all the years in the dataset, and (iii) "detrended" so as to remove interannual variability by subtracting from each year the corresponding seasonal mean. Daily EOFs are then computed from this filtered dataset over the South Pacific sector $70^{\circ}-20^{\circ} \mathrm{S}, 150^{\circ} \mathrm{E}-$ $60^{\circ} \mathrm{W}$. This domain was selected in order to focus on the interannual teleconnections across the extratropical South Pacific identified in Figs. 1a and 5a.

The 700-hPa geopotential height was chosen because low-frequency variability in midlatitudes has an equivalent barotropic vertical structure, and for consistency with previous studies of circulation regimes that used this variable (e.g., Kimoto and Ghil 1993; Michelangeli et al. 1995). Geopotential height at $700 \mathrm{hPa}$ is more closely tied to available surface observations than upperlevel winds, despite a problem with bogus surface pressure observations in the reanalysis (Mo and Higgins 1998). To obtain the largest possible sample size, we use all the years of the NCEP reanalysis dataset, from 1948 to 1999 . There is a trade-off between the longer interval in which the earlier years are more heavily weighted by the NCEP model's behavior, versus using a shorter dataset with a higher observational content. A large sample size is required because we assess the robustness of our results according to their reproducibility in random $50 \%$ subsets of our dataset.

The cluster analysis was performed in the subspace of the 10 leading (intraseasonally filtered) daily PCs, accounting for over $90 \%$ of the total subseasonal variance in all the seasons considered. A point in this 10dimensional PC subspace thus represents each day. This set of points is then partitioned into $K$ clusters, whose centroids minimize the sum of the Euclidean distances between each point and the centroid of its cluster. The clustering was repeated 50 times from different initial seeds, chosen from random $10 \%$ subsets of days, selecting the partition whose cluster centroids are most similar to the other 49 in terms of average pattern correlation-see Michelangeli et al. (1995) for details.

The $K$-means method requires that the number of 
(a) October-December

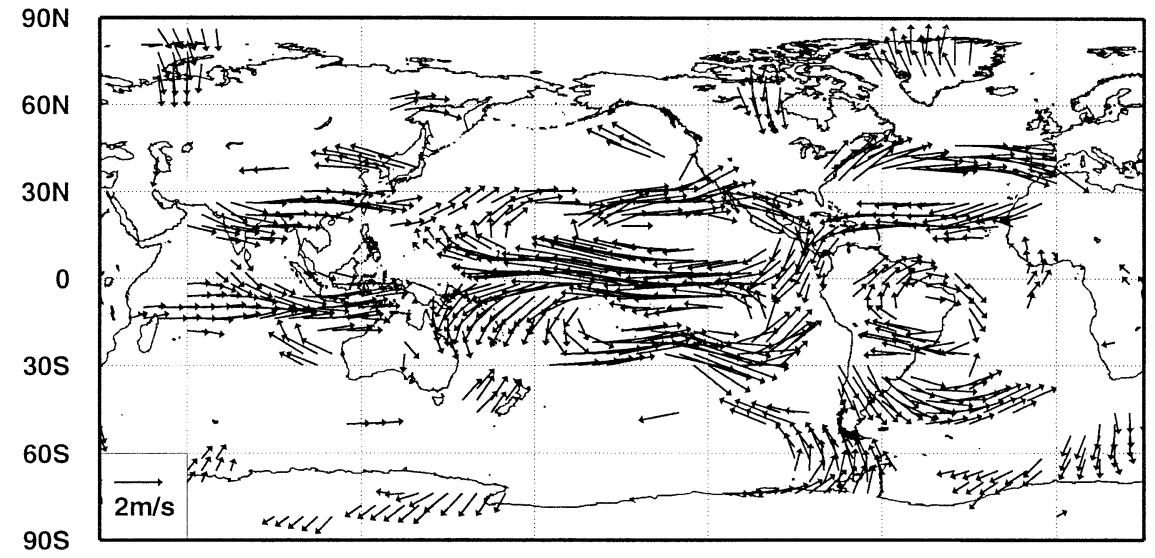

(b) January-February

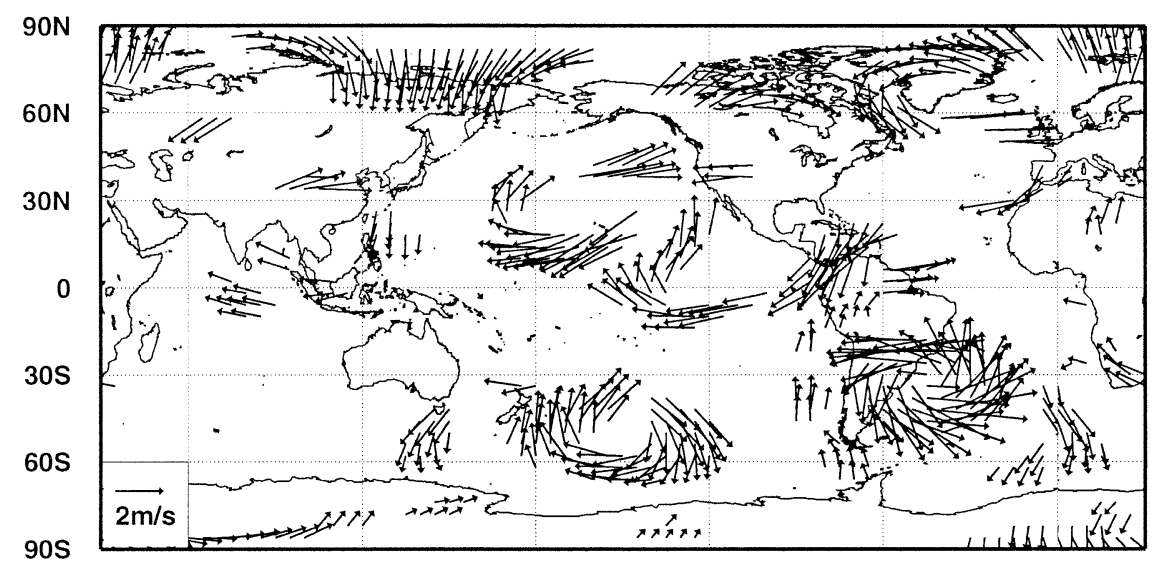

(c) March-July

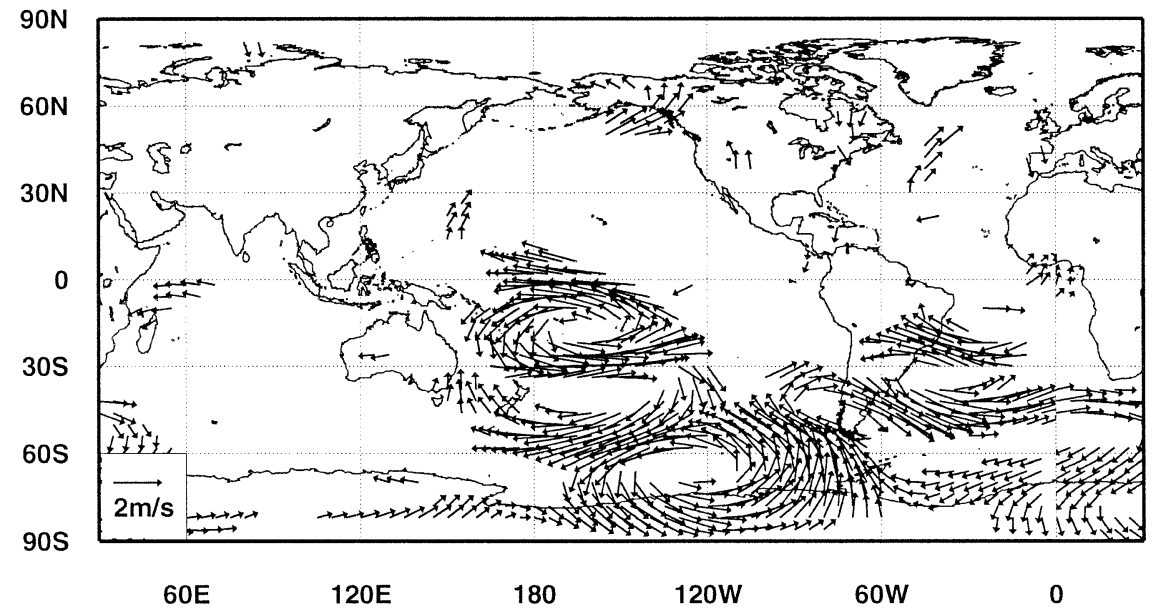

FIG. 6. Regression maps of $200-\mathrm{hPa}$ winds with standardized precipitation in Uruguay in (a) Oct-Dec, (b) Jan-Feb, and (c) Mar-Jul. Only vectors whose correlations with the respective PC are statistically significant at the $95 \%$ level are plotted. 
(a) October

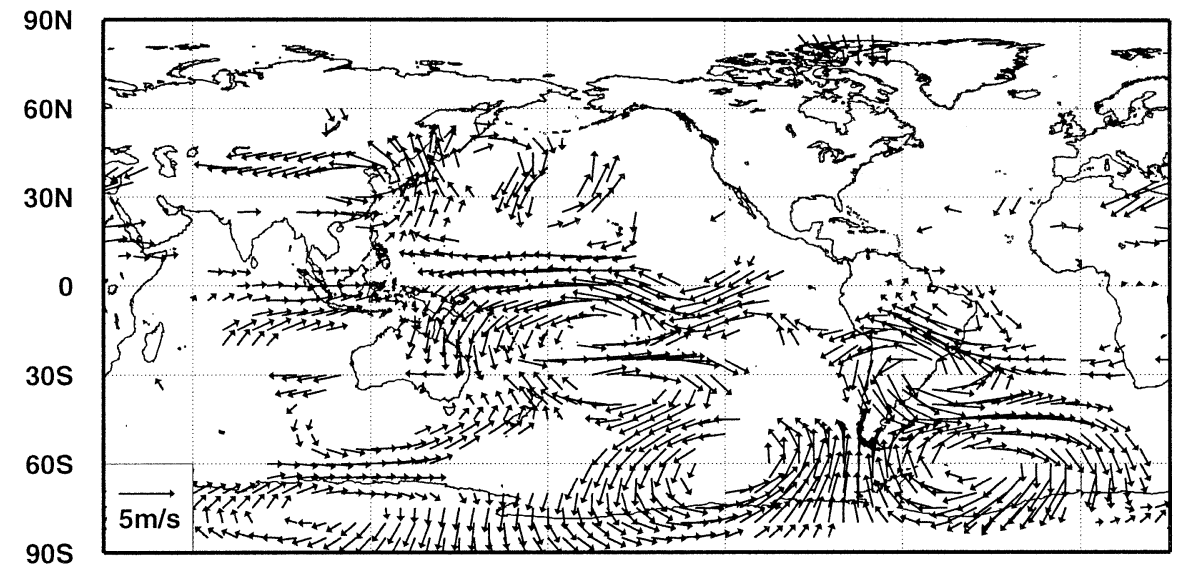

\section{(b) January}

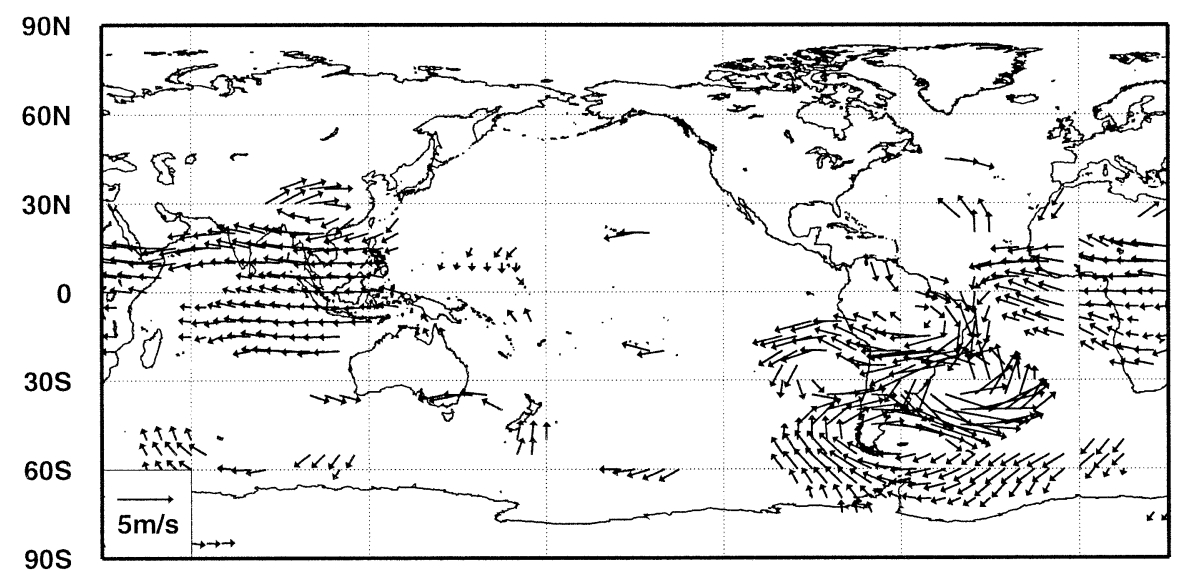

(c) April

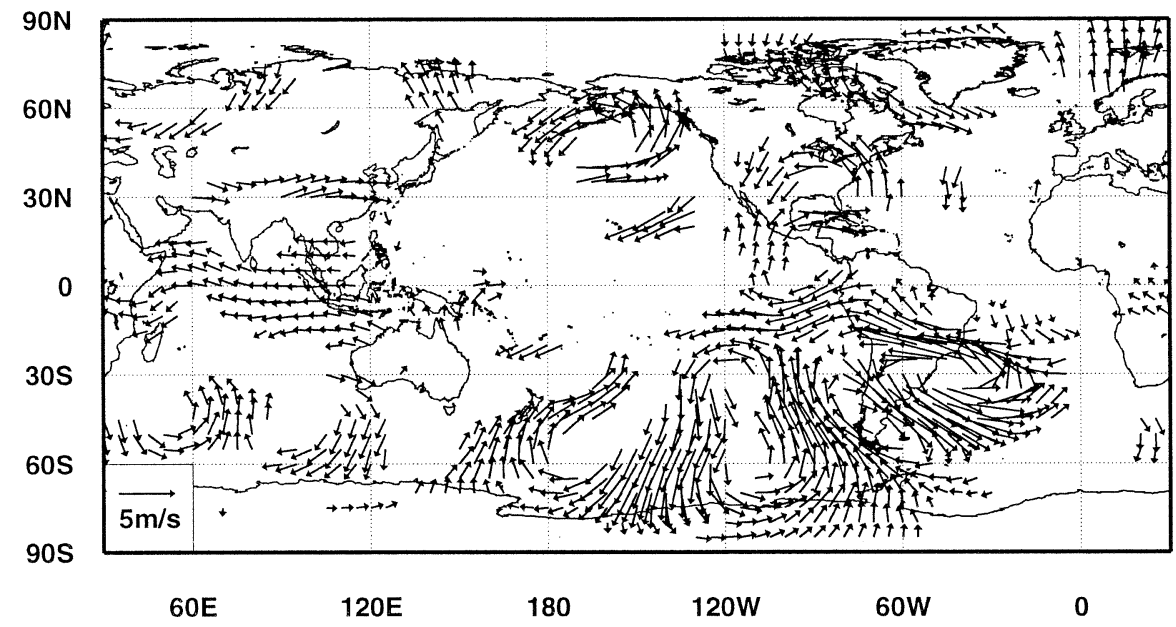

FIG. 7. Regression maps of PC-1 with 200-hPa winds from EOF analyses of the individual calendar months (a) Oct, (b) Jan, and (c) Apr. Only vectors signficant at the 95\% level are plotted. 
(a) October December

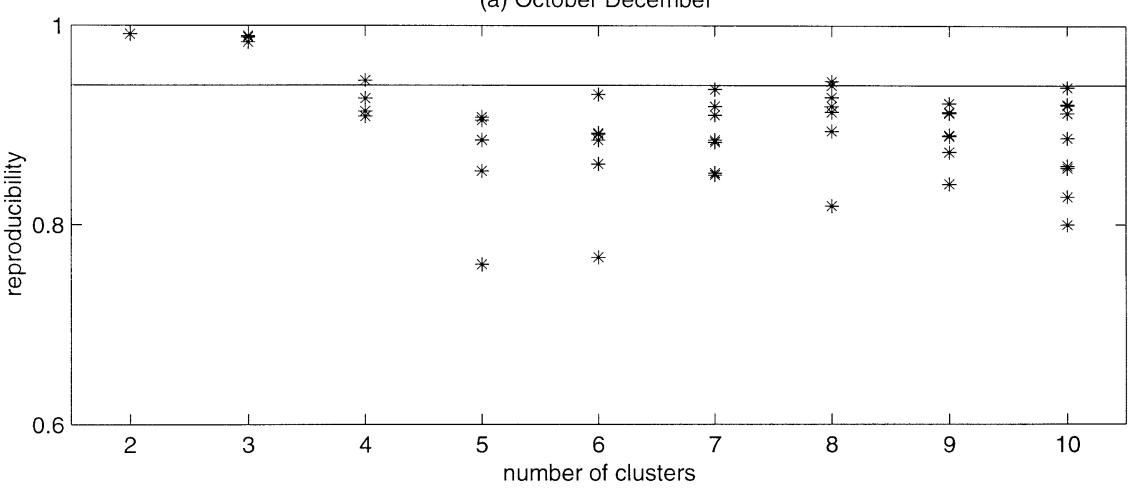

(b) January Februar y

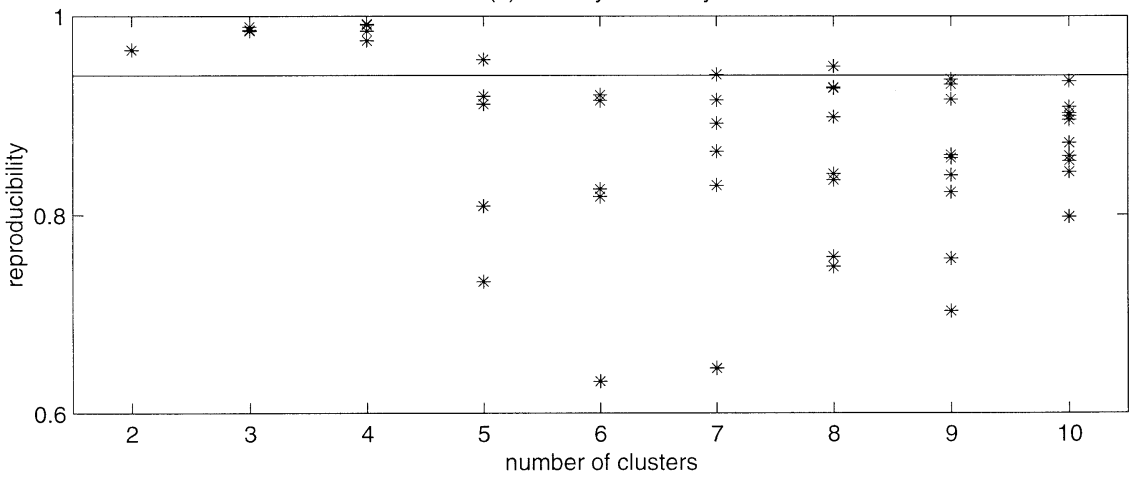

(c) March Jul y

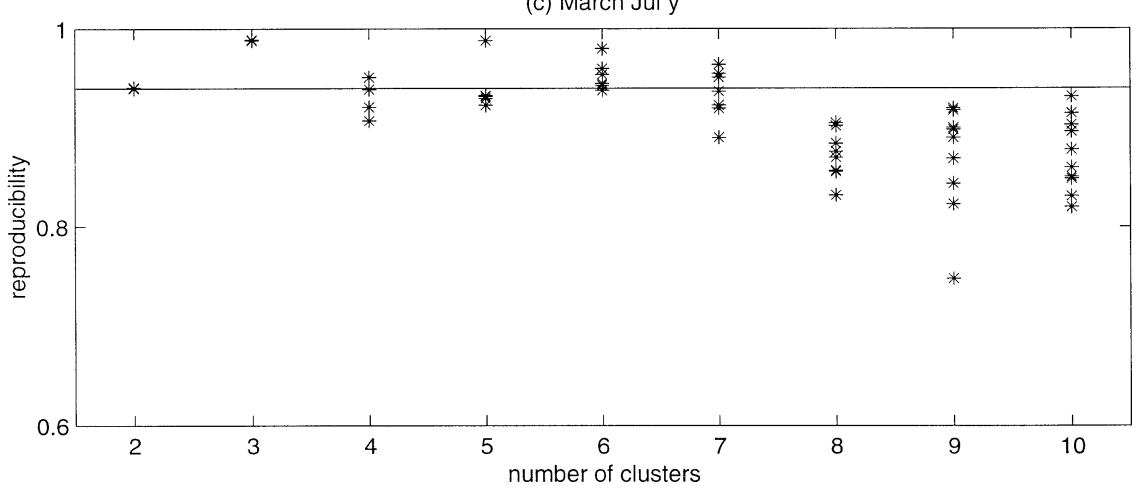

FIG. 8. Reproducibility index $(R)$ of the $K$-means cluster analysis as a function of the number clusters $K$, for (a) Oct-Dec, (b) Jan-Feb, and (c) Mar-Jul. Each star represents the value of $R$ for each cluster, with a value of $R=1$ indicating perfect reproducibility. The horizontal line indicates the $R=0.94$ ad hoc significance value (see text).

clusters $K$ be specified a priori. Following Michelangeli et al. (1995), $K$ was determined so as to obtain optimum reproducibility of each cluster from 50 different random divisions of the 50 -yr dataset into two equal parts. A reproducibility index $(R)$ is defined for each cluster obtained from the full dataset in terms of its average pattern correlation with its counterparts in the 50 half-data subsets. Figure 8 shows the $R$ of each cluster as a function of $K$ for each season. The horizontal line denotes $R=0.94$, which is an ad hoc significance threshold for regional pattern similarity, derived according to the formula proposed by Cheng and Wallace (1993). The $K=$
3 cluster partition has the best reproducibility across all three seasons, while also $K=4$ yields very high reproducibility in January-February. Although $K=2$ has highest reproducibility in October-December, there is essentially only a single anomaly pattern that does not bring any additional information over classic EOF analysis (Michelangeli et al. 1995). We continue our analysis for the case $K=3$ in all seasons. In terms of Michelangeli et al.'s (1995) "classifiability" index (CI) that measures the sensitivity to the 50 different initial seeds, both January-February and March-July are highly insensitive to the choice of initial seeds $(\mathrm{CI}=0.98$ and 

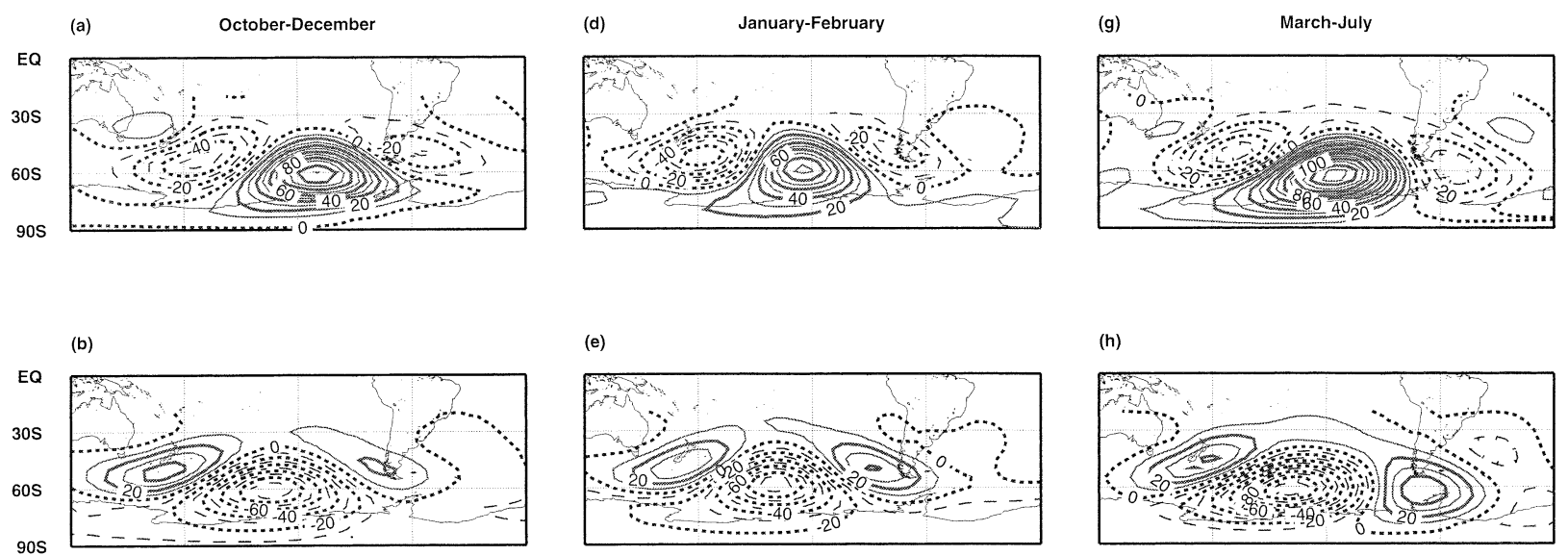

(c)

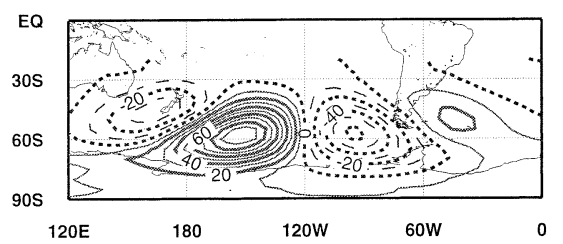

(f)

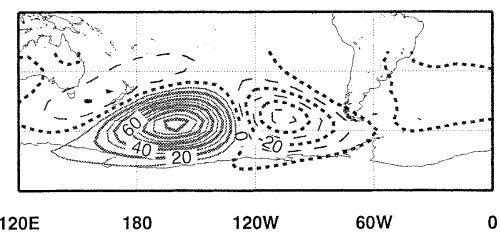

(i)

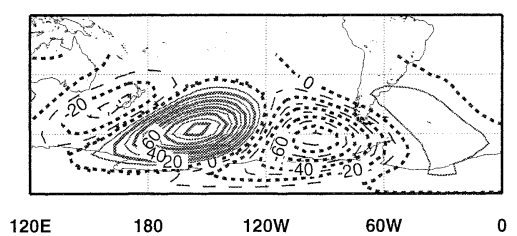

FIG. 9. Intraseasonal regime composites of 700-hPa geopotential height derived from the cluster analysis with $K=3$, for (a)-(c) OctDec, (d)-(f) Jan-Feb, and (g)-(i) Mar-Jul seasons. The contour interval is $20 \mathrm{~m}$.

0.97, respectively; $\mathrm{CI}=1$ for complete insensitivity), while October-December is somewhat more sensitive $(\mathrm{CI}=0.80)$

\section{b. Results}

The cluster centroids are computed from intraseasonally filtered data. In order to study interannual variability in terms of intraseasonal regimes, daily 700-hPa height maps are assigned to each cluster, by projecting the full 700-hPa dataset with interannual variations retained (low pass filtered and deseasonalized) into the intraseasonal EOF subspace, and assigning each day to the nearest centroid. Thus, the centroids are defined from purely intraseasonal variables, from which the seasonal means were subtracted, while cluster membership is determined with seasonal means retained. In this way, interannual variability is assumed to be generated by intrinsic intraseasonal regimes, with year-to-year variations in the number of days spent in each regime.

The circulation regimes constructed in this way are shown in Fig. 9, in terms of composites of the 700-hPa daily geopotential anomalies. Composites derived from purely intraseasonal data have structures that are visually indistinguishable from those in Fig. 9. The regimes have an equivalent-barotropic vertical structure, as seen in Fig. 10 that shows corresponding composites for the $200-\mathrm{hPa}$ daily vector wind field anomalies. The circulation regimes exhibit wavelike structures that are similar in the different seasons considered. These wavelike patterns resemble the PSA type, found through EOF methodology by Kidson (1991), Ghil and Mo (1991) and Mo and Higgins (1998), for the Southern Hemisphere winter (June-August).

Regimes 1 and 2 resemble opposite polarities of the interannual regression maps of EOF-2 for March-July (Fig. 5a) and (to a lesser extent) EOF-1 for OctoberDecember (Fig. 1a) over the South Pacific. It is therefore logical to ask whether these interannual teleconnections over the South Pacific can be interpreted in terms of shifts of the frequency of the intraseasonal circulation regimes in Fig. 9. The relationship between the respective interannual PC (PC-1 for October-December and PC-2 for March-July) and the frequency of occurrence of each regime is shown in Fig. 11, using one standard deviation excursions of the PC to define the seasons where the interannual anomaly is pronounced. The error bars denote the $95 \%$ confidence interval, based on randomly reshuffling an equivalent number of years taken from the whole population 100 times. This analysis was repeated considering samples of neutral years for the random reshuffling, and little sensitivity was found to this change. During October-December, regime 1 occurs significantly more frequently in seasons when PC1 is strongly positive, while regime 2 occurs significantly less frequently (Fig. 11a). Similarly, regime 1 is significantly less frequent, and regime 2 significantly more frequent during years when PC-1 is strongly negative (Fig. 11b). This symmetry and implied linearity is seen clearly in the difference composite (Fig. 11c). 

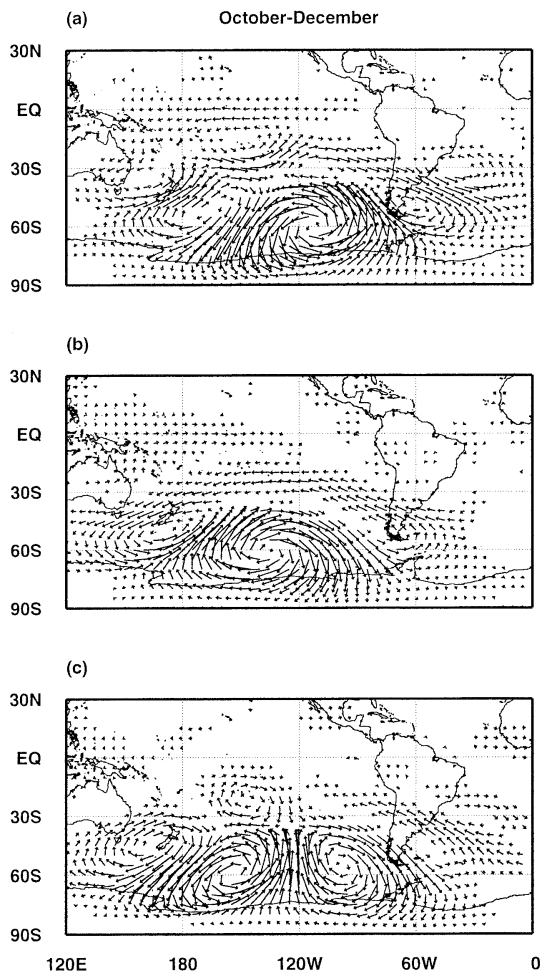

(d)

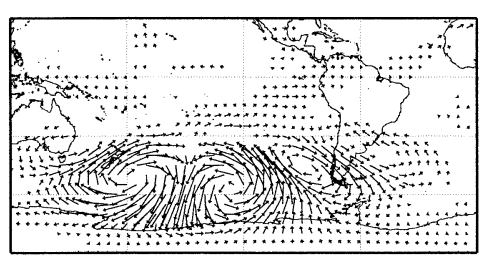

(e)

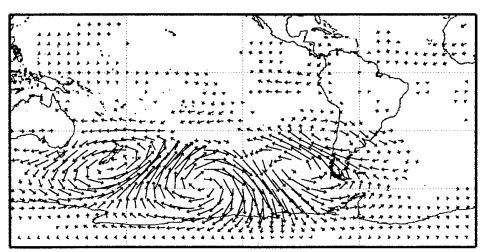

(f)

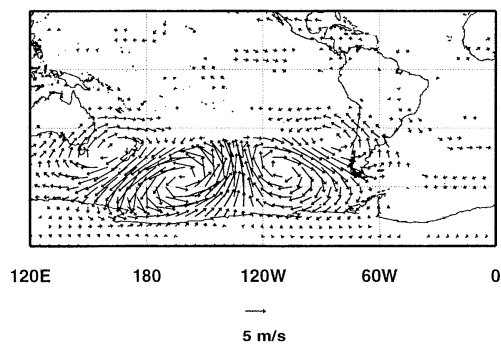

(g) March-July

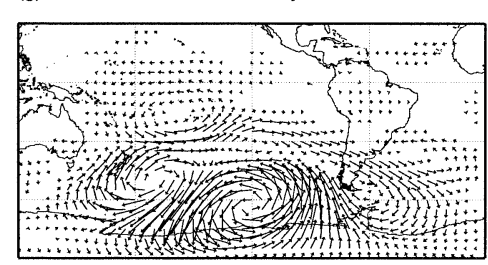

(h)

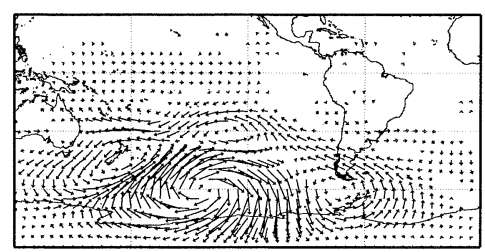

(i)

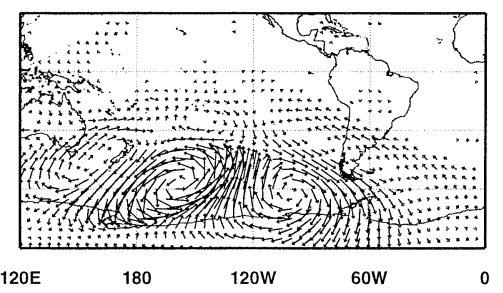

FIG. 10. Same as Fig. 9 but for composites of 200-hPa vector winds. Only vectors that have at least one component statistical significant to the $95 \%$ level are plotted.

During March-July, (Figs. 11d-f) regimes 1 and 2 show an analogous relationship with PC-2. These shifts in the frequency of occurrence of the regimes support the hypothesis that intraseasonal circulation regimes contribute to interannual variability over the South Pacific and South America; a circulation regime that is relatively more frequent leaves a residue after seasonal averaging. By contrast, no significant deviations in regime frequency were found during January-February, consistent with the absence of teleconnections in the interannual EOF analysis.

In order to further test the extent to which the interannual anomalies can be interpreted in terms of the intraseasonal circulation regimes, Fig. 12 shows interannual maps derived solely from linear combinations of the regime composites shown in Fig. 10, weighting each according to its relative change of frequency between years in which the PC in Fig. 11 exceeds plus or minus one standard deviation. Both interannually weighted intraseasonal composites compare reasonably well with the respective interannual EOFs in Figs. 1a and 5a over the extratropical South Pacific region $\left(30^{\circ}-70^{\circ} \mathrm{S}, 150^{\circ} \mathrm{E}-\right.$ $60^{\circ} \mathrm{W}$ ), with pattern correlation of $r=0.69$ for OctoberDecember and $r=0.85$ for March-July, respectively. The March-July match is particularly good, and the regimes reconstruction captures the extratropical part of the interannual pattern. However, the amplitude of the anomalies is underestimated. The root-mean-square (rms) amplitude of EOF-1 averaged over the region considered during October-December is $1.56 \mathrm{~m} \mathrm{~s}^{-1}$, while for the reconstructed pattern it is only $0.71 \mathrm{~m} \mathrm{~s}^{-1}$. For March-July the rms amplitudes are 1.27 and $0.87 \mathrm{~m}$ $\mathrm{s}^{-1}$, respectively. This is consistent with the findings of Farrara et al. (2000) and suggests that interannual tropical heating anomalies influence the amplitude of midlatitude circulation regimes, as well as their frequencies. This is also consistent with the study of Kimoto and Ghil (1993), which found that regime amplitude varies much more than spatial pattern.

The relationships between ENSO and the frequency of occurrence of each circulation regime were investigated in a similar way, using the Niño-3.4 index to define El Niño and La Niña years. Very similar results were found in October-December (not shown), with a weaker relationship in March-July, though with departures of the same sign.

\section{Summary and discussion}

\section{a. Summary}

On interannual timescales the leading EOF of 200$\mathrm{hPa}$ winds over South America is found to be associated with ENSO in all the seasons considered, with a pro- 
October-December

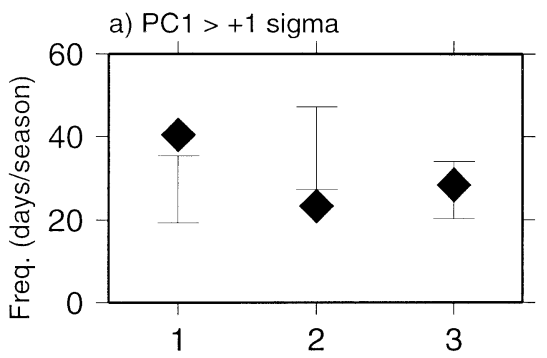

b) $\mathrm{PC} 1<-1$ sigma

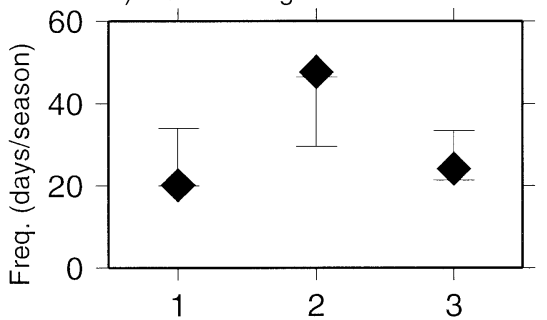

c) difference

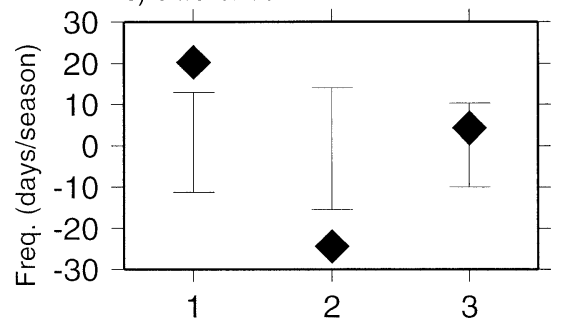

March-July

d) PC2 > +1 sigma

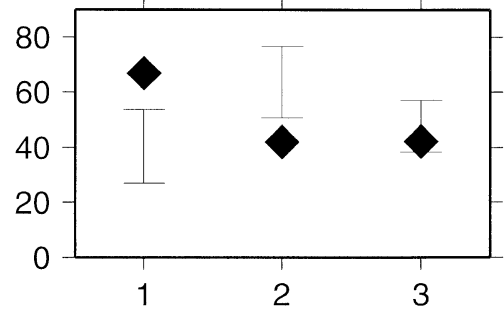

e) PC2 $<-1$ sigma
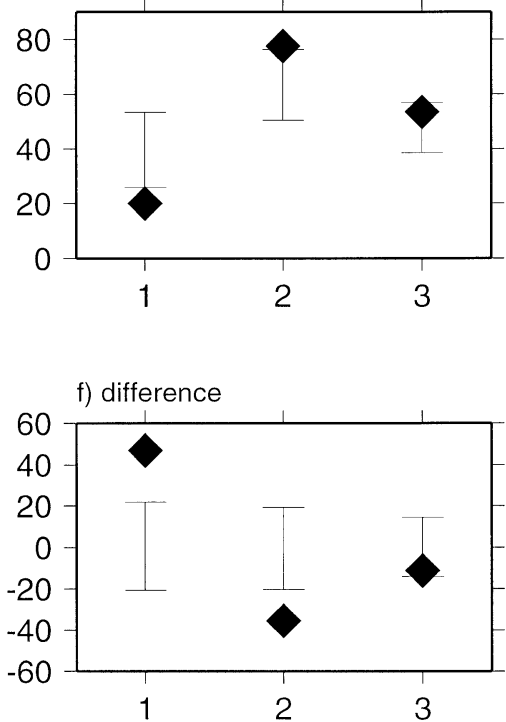

FIG. 11. Regime frequency averaged over seasons in which the corresponding interannual PC exceeds one std dev, for (a)-(c) Oct-Dec with PC-1, and (d)-(f) Mar-Jul with PC-2. The regime number is indicated on the abscissa. Frequencies are shown for (a),(d) positive PC deviations, (b),(e) negative PC deviations, and (c),(f) the differences between them. The "error bars" show the $95 \%$ random sampling range derived from 50 sets of randomly chosen seasons.

nounced equatorial Walker cell component. In austral spring (October-December; Fig. 1) the leading EOF also shows an extratropical teleconnection across the South Pacific with twin anticyclonic (cyclonic) anomalies straddling the equator in the central Pacific, wavelike anomalies over the South Pacific and an eddy over South America centered between SESA and SACZ. The latter is accompanied by a dipole in vertical motion between SESA and the SACZ, consistent with the positive correlation of the $\mathrm{PC}$ and the precipitation in Uruguay. In January-February, this dipolar 500-hPa vertical motion anomalies over SESA along with the 200-hPa wind vortex characterizes EOF-2 (Fig. 3), but unlike during October-December, the latter is not associated with wavelike anomalies over the South Pacific, or with ENSO. In March-July the circulation over extratropical South America is dominated by a wavelike pattern that extends upstream over the South Pacific (EOF-2; Fig. 5). It is not, however, significantly correlated with SST or vertical velocity over the tropical Pacific.

In order to investigate the physical mechanisms associated with the interannual patterns found through EOF analysis and their seasonality, we constructed intraseasonal circulation regimes using a $K$-means clustering analysis of daily $700-\mathrm{hPa}$ geopotential height fields in the South Pacific domain. Three clusters were found to be near optimal in all three seasons (Fig. 8), with very similar wavelike "PSA" spatial structures in each season (Figs. 9 and 10). These PSA structures are similar to those found in previous studies through EOF methodology (Kidson 1991; Mo and Ghil 1987; Mo and Higgins 1998).

We tested the hypothesis that the interannual variability found in the EOF analysis over South America and its upstream teleconnections over the South Pacific could be due to these intrinsic intraseasonal regimes, 
(a)

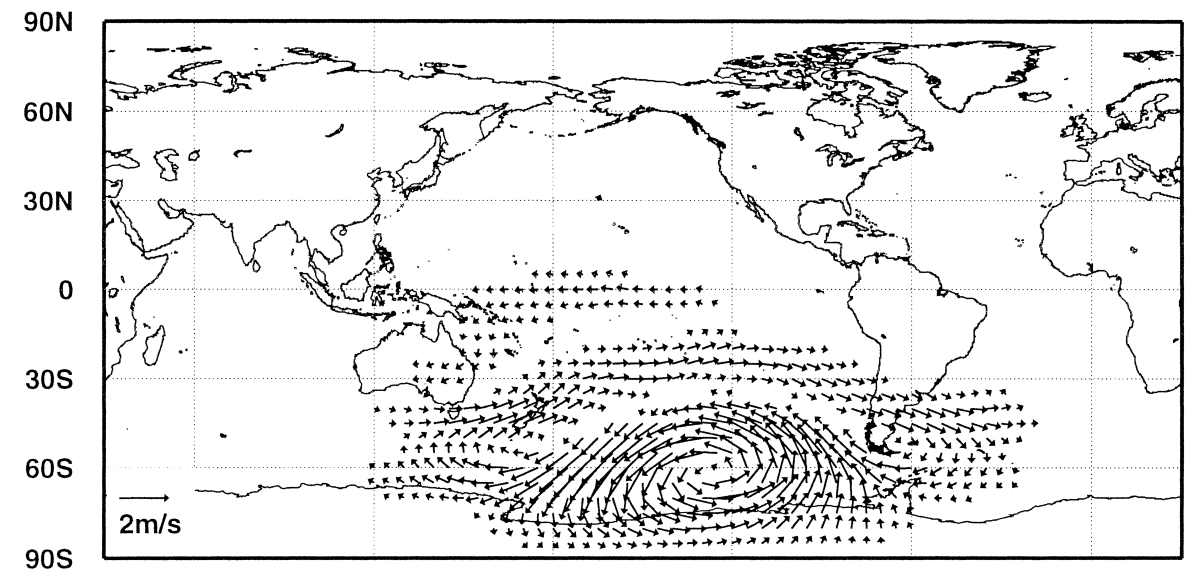

(b)

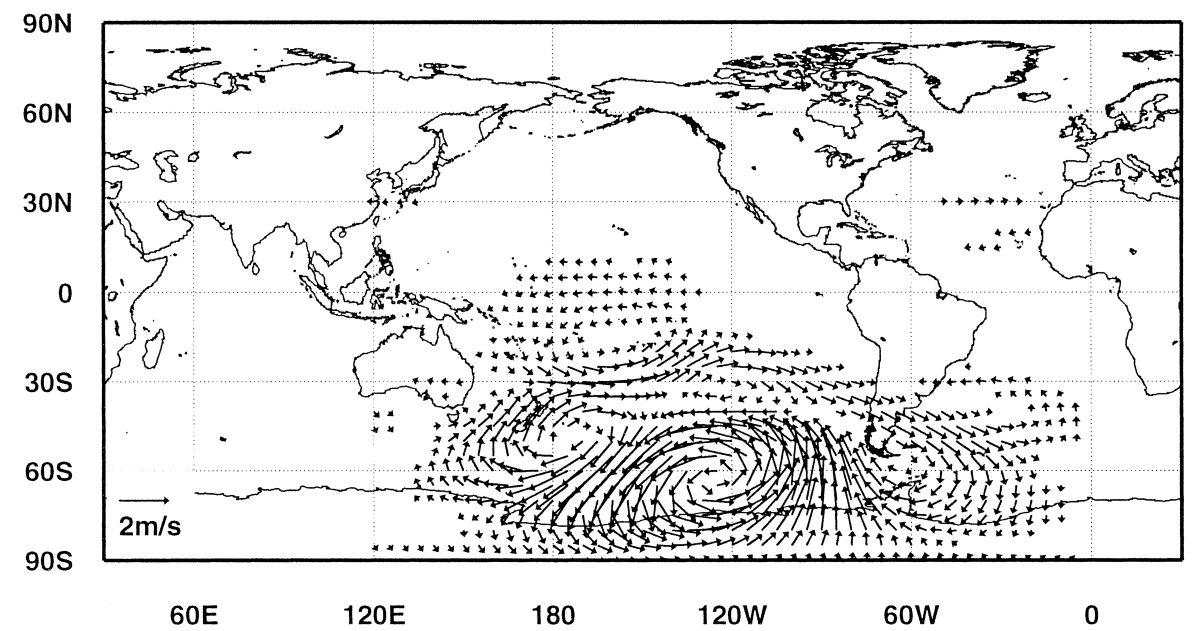

FIG. 12. Regime composites of 200-hPa winds, weighted according to the frequency differences shown in Fig. 11, for (a) Oct-Dec, and (b) Mar-Jul. All the magnitudes have been divided by 2.

through year-to-year variations in the number of days spent in each regime. In October-December, circulation regimes 1 and 2 show opposite and statistically significant shifts in their frequency of occurrence in years where interannual PC-1 is above (or below) one (or minus one) standard deviation (Figs. 11a-c); these shifts are consistent with the polarities of EOF-1. Similar results were obtained for years when the Niño-3.4 index is above (or below) one (or minus one) standard deviation, consistent with the fact that interannual PC-1 for October-December is closely related to ENSO. An interannual $200-\mathrm{hPa}$ wind anomaly pattern was then reconstructed solely as a linear combination of the circulation regimes (Fig. 12a) and was found to compare reasonably well with EOF-1 in the extratropical South Pacific, with a pattern correlation of 0.69. In MarchJuly, regimes 1 and 2 exhibit analogous shifts in fre- quency related to PC-2 (Figs. 11d-f), and the regimereconstructed interannual 200-hPa wind anomalies (Fig. $12 \mathrm{~b})$ is even more similar to the EOF $(r=0.85)$. However, the regime-reconstructed patterns underestimate the amplitude of the interannual anomalies by about $60 \%$ in October-December and 35\% in March-July in an average rms sense. In contrast to the transition seasons, in high summer (January-February), no shifts in the frequency of regime occurrence were found, consistent with the absence of an extratropical teleconnection in the interannual EOF analysis.

\section{b. Discussion}

Our results provide evidence that changes in the frequency- of- occurrence and amplitude of intraseasonal circulation regimes can account for the interannual te- 


\section{(a) October-December}

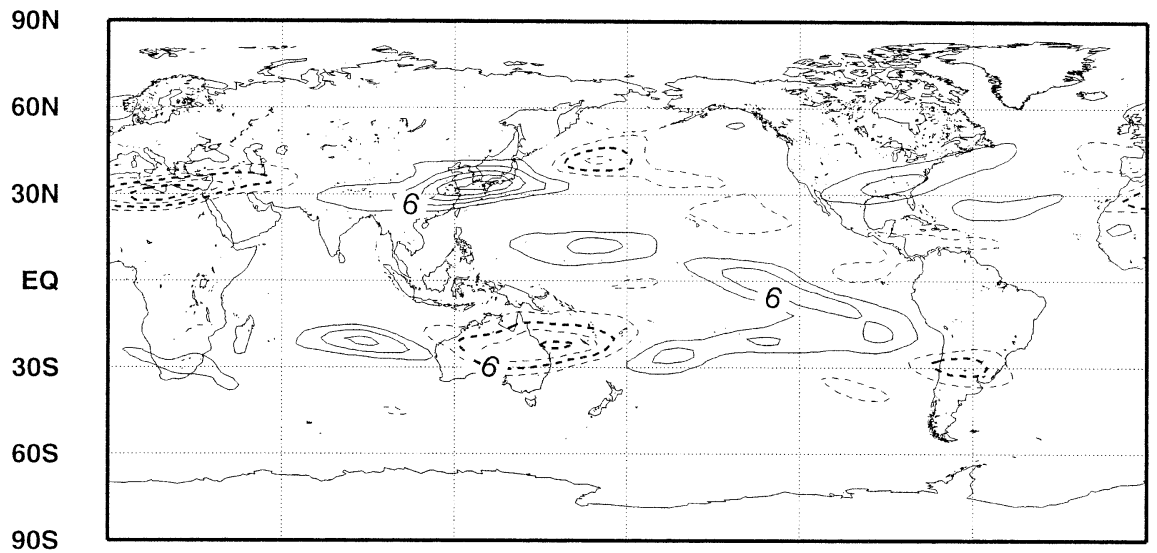

\section{(b) January-February}

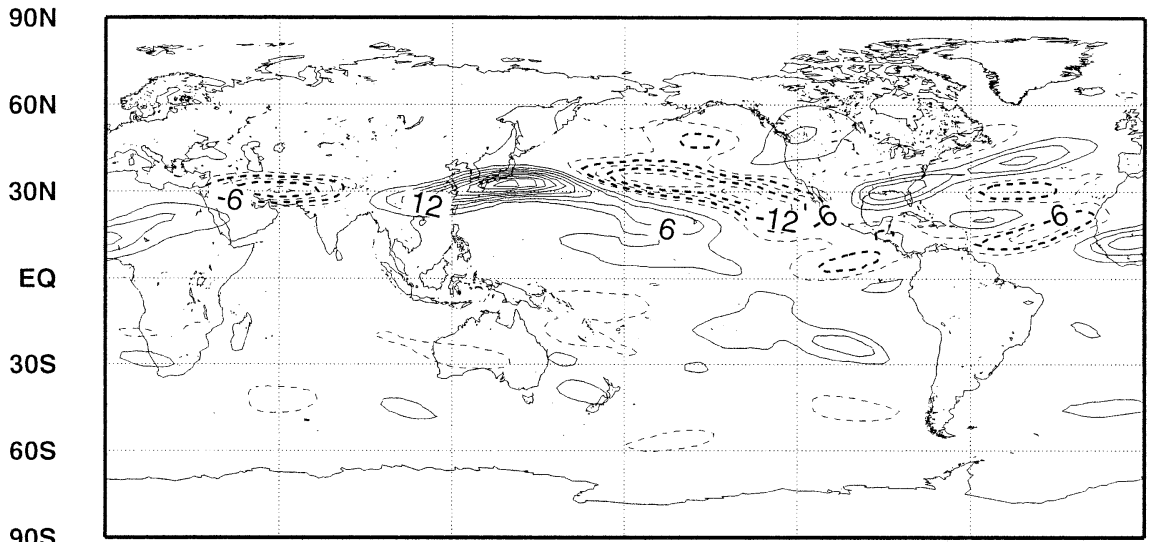

(c) March-July

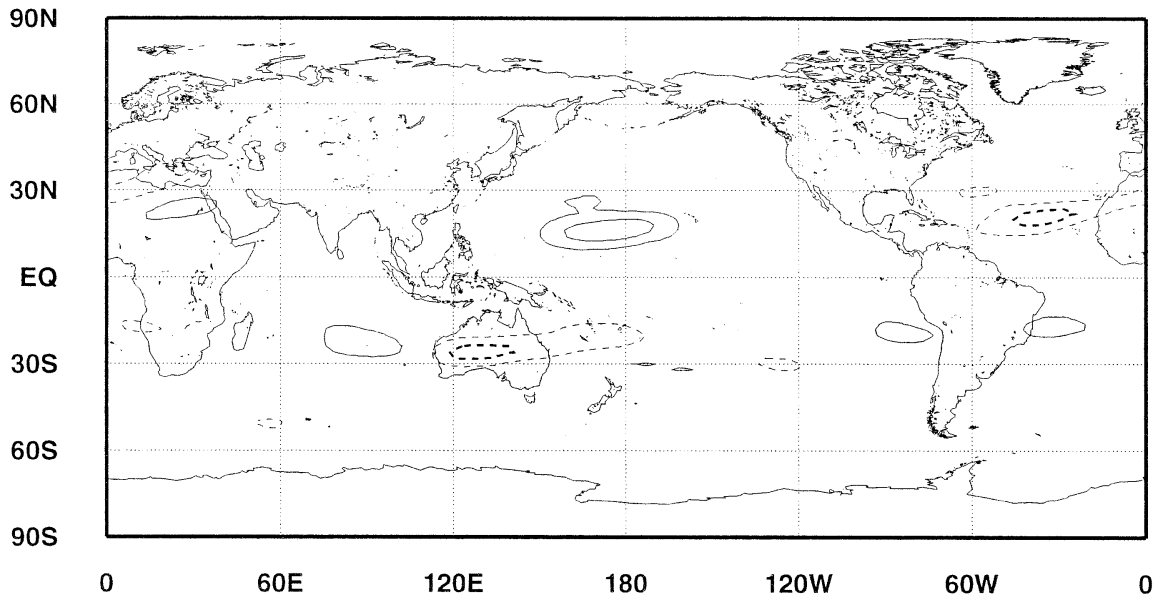

FIG. 13. RWS composite ENSO anomalies, for (a) Oct-Dec, (b) Jan-Feb, and (c) Mar-Jul. Contour interval is $5 \times 10^{-11} \mathrm{~s}^{-2}$. The years used in (a) are the El Niño years 1972, 1976, 1982, 1986, 1991, 1994, 1997, minus the La Niña years 1970, 1971, 1973, 1975, 1984, 1988, 1995, with the year +1 used in (b) and (c). 
(a)

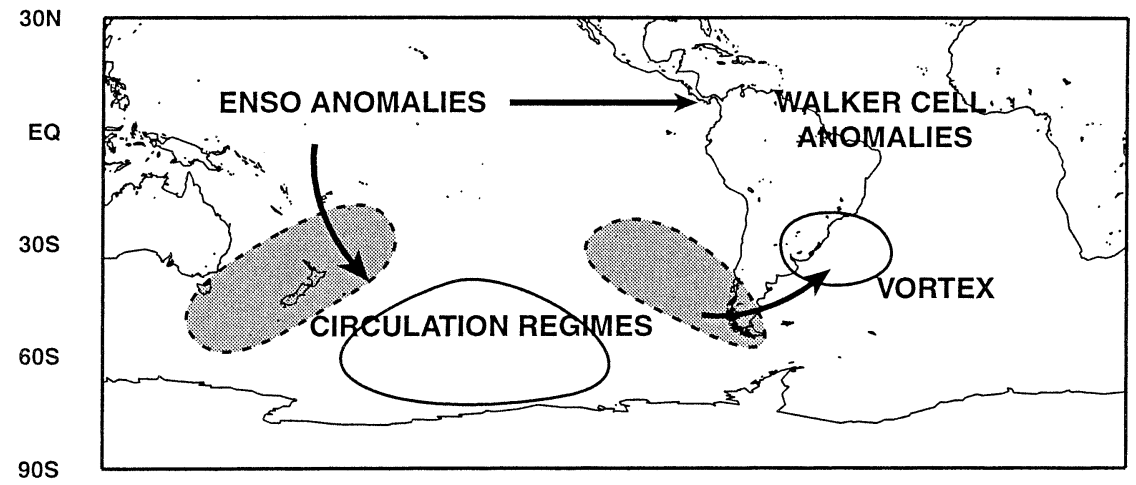

(b)

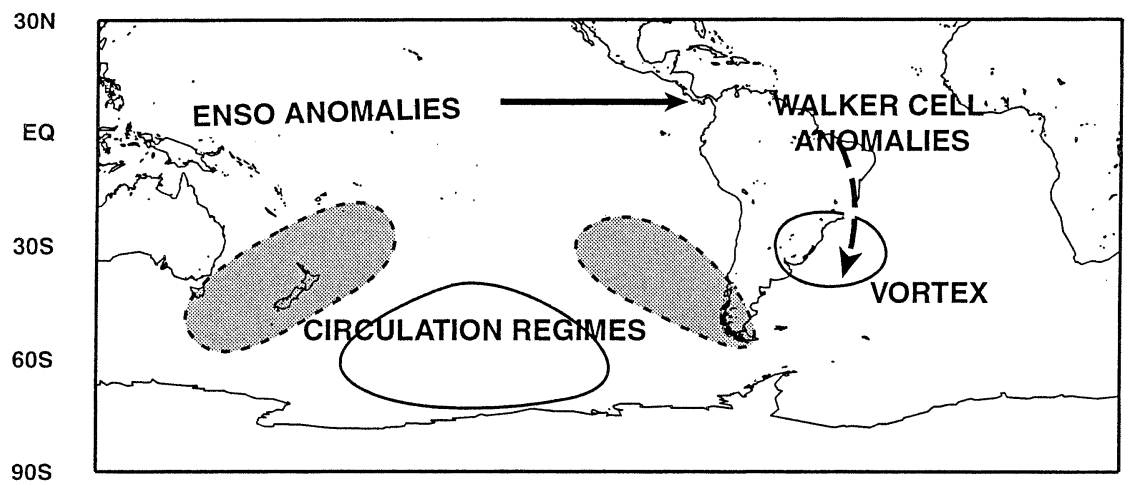

(c)

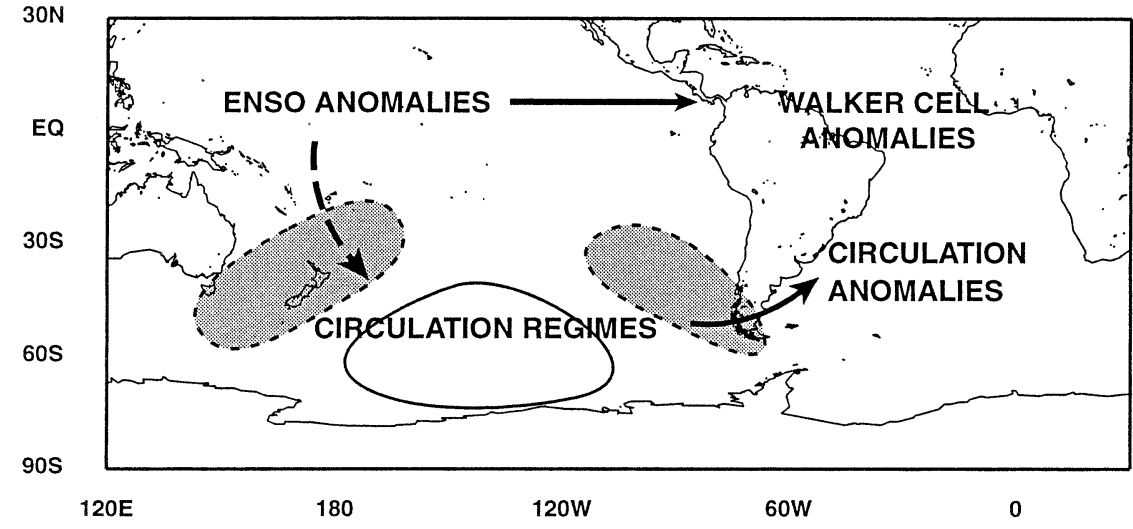

FIG. 14. Schematic of the links between the circulation anomalies over South America, the intraseasonal South Pacific circulation regimes and ENSO, for (a) Oct-Dec, (b) Jan-Feb, and (c) Mar-Jul. The full arrows indicate strong relationships found, while the dotted arrows suggest weaker relationships. See text for further details.

leconnection patterns over the South Pacific in the austral spring and fall-winter. Similar findings have been reported over the North Pacific-North American sector by Horel and Mechoso (1988), Molteni et al. (1993), Robertson and Ghil (1999), and Farrara et al. (2000).
In these studies, interannual anomalies are interpreted as the "residue" obtained from time-averaging intrinsic circulation regimes that have geographically fixed spatial patterns with a given polarity. Over the South $\mathrm{Pa}$ cific, however, Mo and Higgins (1998) have argued that 
intraseasonal variability is characterized by eastward propagating PSA Rossby waves. We find that in October-December and in March-July a particular number of clusters $(K=3)$ was strongly preferred in terms of reproducibility, suggesting that circulation regimes do exist defined as recurrent and persistent quasi-stationary intrinsic modes. Robertson and Mechoso (2003) have examined the propagating component of the PSA patterns on intraseasonal timescales and found it to be small.

Two aspects of the relationship between the interannual EOFs and the intraseasonal regimes deserve further comment. First, the regimes are confined to the extratropical South Pacific, while the interannual teleconnections arch poleward from the tropical Pacific and tend to arch back equatorward into South America, especially in March-July. This difference remains even when the regimes are plotted in terms of 200-hPa wind anomalies. The teleconnections in March-July resemble the great-circle paths of tropically forced Rossby wave dispersion (Hoskins and Karoly 1981). Thus, while the intraseasonal regimes are substantially implicated in accounting for the interannual teleconnections, the tailend over extratropical South America may be due to processes associated with intrinsic modes of variability of the SACZ. The second aspect of the intraseasonalinterannual differences concerns seasonality: the regime patterns exhibit little change between the seasons while the interannual teleconnection pattern across the South Pacific vanishes in high summer, along with the link between ENSO and extratropical South America.

To investigate further the role of tropical forcing and its seasonality, we have computed the Rossby wave source (RWS; Sardeshmukh and Hoskins 1988), which accounts for the vorticity tendency due to both the divergence term as well as the advection of vorticity by the divergent wind. Figure 13 shows the RWS anomalies at $200 \mathrm{hPa}$ for a composite difference between El Niño and La Niña years (Trenberth 1997), for October-December, January-February, and March-July. During October-December there is a large negative source over Australia that disappears in January-February when anomalies in RWS are largely north of the equator. In March-July the RWS anomalies over Australia return but are significantly weaker.

The main interrelationships discussed between the interannual circulation anomalies over South America, the intraseasonal South Pacific circulation regimes, and ENSO are summarized schematically in Fig. 14. Our results suggest that during October-December, the RWS associated with El Niño latent heating anomalies (Fig. 13) generates Rossby waves that favor regime 1 at the expense of regime 2. The interannual vortex over SESA lies at the tail end of the intraseasonal regime patterns, and is likely to be influenced by them. During JanuaryFebruary, there are no RWS anomalies that can "trigger" changes in regime frequency. This is consistent with the seasonal changes in the climatological merid- ional vorticity gradient, which is weaker and is shifted poleward during summer. The interannual vortex over SESA, found by Robertson and Mechoso (2000) to be characterized by stationary Rossby wave extratropical dynamics, appears to be negligibly affected by the regimes over the South Pacific in January-February, but Fig. 2 suggests that interactions with equatorial anomalies over Brazil may be important during ENSO years, pointing toward the geographical complexity of ENSO teleconnections and their seasonal dependence over South America (Grimm et al. 2000). In March-July, the anomalous RWS over the subtropical South Pacific returns, but is much weaker that in October-December. This is consistent with a lower "ENSO signal" to "midlatitude noise" ratio in this season. The interannual teleconnection pattern seen in March-July can be interpreted consistently as "climate noise" (Feldstein 2000) resulting from an essentially random residue of intraseasonal regimes. As a final caveat, we note that the South Pacific sector is a data-sparse region so that more definitive answers to these issues must await more complete future observational datasets.

Acknowledgments. We are grateful to Gregoire Kerneis for some of the circulation regime analyses. AWR's work was supported by NOAA Grant NA06GPO427. GCB's work was supported by IAI Cooperative Agreement ATM-920981, Subaward UCAR S97-74046, UCAR-UR, and by the project IAI-ISP3-0076.0. CRM was partially supported by NOAA Grant NA06GP0511.

\section{REFERENCES}

Aceituno, P., 1989: On the functioning of the Southern Oscillation in the South American sector. Part II: Upper-air circulation. J. Climate, 2, 341-355.

Barros, V., M. Gonzalez, B. Liebmann, and I. Camilloni, 2000: Influence of the South Atlantic convergence zone and South Atlantic Sea surface temperature on interannual summer rainfall variability in southeastern South America. Theor. Appl. Climatol., 67, 123-133.

Bauer, F., 1951: Extended-range weather forecasting. Compendium of Meteorology, T. F. Malone, Ed., Amer. Meteor. Soc., 814833.

Branstator, G., 1985: Analysis of general circulation model sea surface temperature anomaly simulations using a linear model. Part II: Eigenanalysis. J. Atmos. Sci., 42, 2242-2254.

Casarin, D. P., and V. E. Kousky, 1986: Anomalias de precipitacao no sul do Brasil e variacoes na circulacao de atmosferica (Precipitation anomalies in south Brazil and variations in atmospheric circulation). Rev. Bras. Meteor., 1, 83-90.

Chen, W. Y., 1982: Fluctuations in Northern Hemisphere $700 \mathrm{mb}$ height field associated with the Southern Oscillation. Mon. Wea. Rev., 110, 808-823.

Cheng, X., and J. M. Wallace, 1993: Cluster analysis in the Northern Hemisphere wintertime 500-hPa height field: Spatial patterns. $J$. Atmos. Sci., 50, 2674-2696.

Dole, R. M., and N. M. Gordon, 1983: Persistent anomalies of the extratropical Northern Hemisphere winter time circulation: Geographical distribution and regional persistence characteristics. Mon. Wea. Rev., 111, 1567-1586.

Farrara, J. D., C. R. Mechoso, and A. W. Robertson, 2000: Ensembles of AGCM two-tier predictions and simulations of the circulation 
anomalies during winter 1997-1998. Mon. Wea. Rev., 128, $3589-3604$

Feldstein, S. B., 2000: Is interannual zonal mean flow variability simply climate noise? J. Climate, 13, 2356-2362.

Ghil, M., and S. Childress, 1987: Topics in Geophysical Fluid Dynamics: Atmospheric Dynamics, Dynamo Theory, and Climate Dynamics. Springer-Verlag, 485 pp.

— , and K. C. Mo, 1991: Intraseasonal oscillations in the global atmosphere. Part II: Southern Hemisphere. J. Atmos. Sci., 48, 780-790.

Gill, A. E., 1980: Some simple solutions for heat induced tropical circulations. Quart. J. Roy. Meteor. Soc., 106, 447-462.

Grimm, A. M., V. R. Barros, and M. E. Doyle, 2000: Climate variability in southern South America associated with El Niño and La Niña events. $J$. Climate, 13, 35-58.

Held, I. M., S. W. Lyons, and S. Nigam, 1989: Transients and the extratropical response to El Niño. J. Atmos. Sci., 46, 163-174.

Horel, J., and C. R. Mechoso, 1988: Observed and simulated intraseasonal variability of the wintertime planetary circulation. $J$. Climate, 1, 582-599.

Hoskins, B. J., and D. Karoly, 1981: The steady linear response of a spherical atmosphere to thermal and orographic forcing. $J$. Atmos. Sci., 38, 1179-1196.

Kalnay, E., and Coauthors, 1996: The NECP/NCAR 40-Year Reanalysis Project. Bull. Amer. Meteor. Soc., 77, 437-471.

Kidson, J. W., 1988: Interannual variation in the Southern Hemisphere circulation. J. Climate, 1, 1177-1198.

_ 1991: Intraseasonal variation in the Southern Hemisphere circulation. J. Climate, 4, 939-953.

Kimoto, M., and M. Ghil, 1993: Multiple flow regimes in the Northern Hemisphere winter. Part I: Methodology and hemispheric regimes. J. Atmos. Sci., 50, 2645-2673.

Legras, B., and M. Ghil, 1985: Persistent anomalies, blocking and variations in atmospheric predictability. J. Atmos. Sci., 42, 433471.

Liebmann, B., G. N. Kiladis, J. A. Marengo, T. Ambrizzi, and J. D. Glick, 1999: Submonthly convective variability over South America and the South Atlantic convergence zone. J. Climate, 12, 1877-1891.

Michelangeli, P. A., R. Vautard, and B. Legras, 1995: Weather regimes: Recurrence and quasi stationarity. J. Atmos. Sci., 52, $1237-1256$.
Mo, K. C., and M. Ghil, 1987: Statistical dynamics of persistent anomalies. J. Atmos. Sci., 44, 877-901.

— and tropical convection during the Southern Hemisphere winter. Mon. Wea. Rev., 126, 1581-1596.

Molteni, F., L. Ferranti, T. N. Palmer, and P. Viterbo, 1993: A dynamical interpretation of the global response to equatorial Pacific SST anomalies. J. Climate, 6, 777-795.

Nogués-Paegle, J., and K. C. Mo, 1997: Alternating wet and dry conditions over South America during summer. Mon. Wea. Rev. 125, 279-291.

— L. A. Byerle, and K. C. Mo, 2000: Intraseasonal modulation of South American summer precipitation. Mon. Wea. Rev., 128, $837-850$

Pisciottano, G., A. Diaz, G. Cazes, and C. R. Mechoso, 1994: El Niño-Southern Oscillation impact on rainfall in Uruguay. J. Climate, 7, 1286-1302.

Rayner, N. A., C. K. Folland, D. E. Parker, and E. B. Horton, 1995: A new global sea-ice and sea surface temperature (GISST) data set for 1903-1994 for forcing climate models. Hadley Centre Internal Note $69,13 \mathrm{pp}$

Richman, M. B., 1986: Rotation of principal components. J. Climatol., 6, 293-335.

Robertson, A. W., and M. Ghil, 1999: Large-scale weather regimes and local climate over the western United States. J. Climate, 12, $1796-1813$.

_ and C. R. Mechoso, 2000: Interannual and interdecadal variability of the South Atlantic convergence zone. Mon. Wea. Rev. 128, 2947-2957.

_ and - 2003: Circulation regimes and low-frequency oscillations in the South Pacific sector. Mon. Wea. Rev., in press

Sardeshmukh, P. D., and B. J. Hoskins, 1988: The generation of global rotational flow by steady idealized tropical divergence. J. Atmos. Sci., 45, 1228-1251.

Trenberth, K. E., 1997: A definition of El Niño. Bull. Amer. Meteor Soc., 78, 2771-2777.

Vautard, R., 1990: Multiple weather regimes over the North Atlantic: Analysis of precursors and succesors. Mon. Wea. Rev., 118, 2056-2081.

Wallace, J., and D. Gutzler, 1981: Teleconnections in the geopotential height field during the Northern Hemisphere winter. Mon. Wea. Rev., 109, 784-812. 